Cochrane Database of Systematic Reviews

\title{
Adenosine versus intravenous calcium channel antagonists for supraventricular tachycardia (Review)
}

Alabed S, Sabouni A, Providencia R, Atallah E, Qintar M, Chico TJA

Alabed S, Sabouni A, Providencia R, Atallah E, Qintar M, Chico TJA.

Adenosine versus intravenous calcium channel antagonists for supraventricular tachycardia.

Cochrane Database of Systematic Reviews 2017, Issue 10. Art. No.: CD005154.

DOI: 10.1002/14651858.CD005154.pub4.

www.cochranelibrary.com 
TABLE OF CONTENTS

HEADER

ABSTRACT

PLAIN LANGUAGE SUMMARY

SUMMARY OF FINDINGS

BACKGROUND

OBJECTIVES

METHODS

RESULTS

Figure 1.

Figure 2.

Figure 3.

DISCUSSION

AUTHORS' CONCLUSIONS

ACKNOWLEDGEMENTS

REFERENCES

CHARACTERISTICS OF STUDIES

DATA AND ANALYSES

Analysis 1.1. Comparison 1 Adenosine vs CCA, Outcome 1 Odds of reversion.

Analysis 1.2. Comparison 1 Adenosine vs CCA, Outcome 2 Time to reversion (seconds).

Analysis 1.3. Comparison 1 Adenosine vs CCA, Outcome 3 Relapse to SVT post reversion.

Analysis 1.4. Comparison 1 Adenosine vs CCA, Outcome 4 Minor adverse events.

Analysis 1.5. Comparison 1 Adenosine vs CCA, Outcome 5 Hypotension. 
[Intervention Review]

\section{Adenosine versus intravenous calcium channel antagonists for supraventricular tachycardia}

Samer Alabed ${ }^{1}$, Ammar Sabouni2 $^{2}$, Rui Providencia 3 , Edmond Atallah", Mohammed Qintar ${ }^{5}$, Timothy JA Chico6

1Academic Unit of Radiology, University of Sheffield, Sheffield, UK. ${ }^{2}$ KasrAlAiny School of Medicine, Cairo University, Cairo, Egypt. ${ }^{3}$ Barts Heart Centre, St Bartholomew's Hospital, Barts Health NHS Trust, London, UK. “Department of Gastroenterology, Nottingham University Hospitals NHS Trust, Nottingham, UK. ${ }^{5}$ Department of Cardiovascular Medicine, Saint Luke's Mid America Heart Institute; University of Missouri-Kansas City, Kansas City, MO, USA. ${ }^{6}$ Department of Infection, Immunity and Cardiovascular Disease, University of Sheffield, Sheffield, UK

Contact address: Samer Alabed, Academic Unit of Radiology, University of Sheffield, Sheffield, UK. s.alabed@sheffield.ac.uk, s.alabed@nhs.net.

Editorial group: Cochrane Heart Group.

Publication status and date: New search for studies and content updated (conclusions changed), published in Issue 10, 2017.

Citation: Alabed S, Sabouni A, Providencia R, Atallah E, Qintar M, Chico TJA. Adenosine versus intravenous calcium channel antagonists for supraventricular tachycardia. Cochrane Database of Systematic Reviews 2017, Issue 10. Art. No.: CD005154. DOI: 10.1002/14651858.CD005154.pub4.

Copyright @ 2017 The Cochrane Collaboration. Published by John Wiley \& Sons, Ltd.

\section{A B S T R A C T}

\section{Background}

People with supraventricular tachycardia (SVT) frequently are symptomatic and present to the emergency department for treatment. Although vagal manoeuvres may terminate SVT, they often fail, and subsequently adenosine or calcium channel antagonists (CCAs) are administered. Both are known to be effective, but both have a significant side effect profile. This is an update of a Cochrane review previously published in 2006 .

\section{Objectives}

To review all randomised controlled trials (RCTs) that compare effects of adenosine versus CCAs in terminating SVT.

\section{Search methods}

We identified studies by searching CENTRAL, MEDLINE, Embase, and two trial registers in July 2017. We checked bibliographies of identified studies and applied no language restrictions.

\section{Selection criteria}

We planned to include all RCTs that compare adenosine versus a CCA for patients of any age presenting with SVT.

\section{Data collection and analysis}

We used standard methodological procedures as expected by Cochrane. Two review authors independently checked results of searches to identify relevant studies and resolved differences by discussion with a third review author. At least two review authors independently assessed each included study and extracted study data. We entered extracted data into Review Manager 5. Primary outcomes were rate of reversion to sinus rhythm and major adverse effects of adenosine and CCAs. Secondary outcomes were rate of recurrence, time to reversion, and minor adverse outcomes. We measured outcomes by calculating odds ratios (ORs) and assessed the quality of primary outcomes using the GRADE approach through the GRADEproGDT website. 


\section{Main results}

We identified two new studies for inclusion in the review update; the review now includes seven trials with 622 participants who presented to an emergency department with SVT. All included studies were RCTs, but only three described the randomisation process, and none had blinded participants, personnel, or outcome assessors to the intervention given. Moderate-quality evidence shows no differences in the number of people reverting to sinus rhythm who were treated with adenosine or CCA $(89.7 \%$ vs $92.9 \%$; OR 1.51 , 95\% confidence interval (Cl) 0.85 to 2.68 ; participants $=622$; studies $=7 ; 1^{2}=36 \%$ ). Low-quality evidence suggests no appreciable differences in major adverse event rates between CCAs and adenosine. Researchers reported only one case of hypotension in the CCA group and none in the adenosine group ( $0.66 \%$ vs $0 \%$; OR $3.09,95 \% \mathrm{Cl} 0.12$ to 76.71 ; participants $=306$; studies $\left.=3 ;\left.\right|^{2}=0 \%\right)$. Included trials did not report length of stay in hospital nor patient satisfaction.

\section{Authors' conclusions}

Moderate-quality evidence shows no differences in effects of adenosine and calcium channel antagonists for treatment of SVT on reverting to sinus rhythm, and low-quality evidence suggests no appreciable differences in the incidence of hypotension. A study comparing patient experiences and prospectively studied adverse events would provide evidence on which treatment is preferable for management of SVT.

\section{PLAIN LANGUAGE SUMMARY}

\section{Adenosine versus intravenous calcium channel antagonists for tachycardia in adults}

\section{Background}

Supraventricular tachycardia (SVT) is a common abnormal rhythm of the heart that results in a very rapid heartbeat. This rhythm problem usually occurs in otherwise healthy people, and common symptoms include palpitations, light-headedness, and chest pain. Occasionally, SVT may also cause confusion or loss of consciousness. SVT can sometimes be treated with simple physical manoeuvres such as forced breath holding. When simple manoeuvres fail, SVT can be treated in the emergency department with a variety of drugs. The two most commonly used drug types are adenosine and calcium channel antagonists (CCAs) (verapamil is the most frequently used drug in this class).

\section{Study characteristics}

This review compares effectiveness and side effects of adenosine and CCAs in terminating SVT episodes. We included in the review seven trials involving 622 patients. Evidence is current to July 2017.

\section{Key results}

Combined analysis of these trials showed no differences between adenosine and CCAs in successfully treating SVT. This finding is based on moderate-quality evidence. A temporary drop in blood pressure that did not require treatment was reported in only one of 152 study participants treated with CCAs, and low-quality evidence suggests that no patients treated with adenosine experienced low blood pressure. We have no data on length of stay in hospital nor on patient satisfaction.

\section{Conclusions}

Moderate-quality evidence shows no differences in effects of adenosine and calcium channel antagonists for treatment of SVT on reverting to sinus rhythm, and low-quality evidence suggests no differences in cases of hypotension. None of these trials examined patient preferences, which is an important factor in deciding which drug is the 'best' treatment. 
SUMMARY OF FINDINGS

Summary of findings for the main comparison. Adenosine compared with calcium channel antagonists for supraventricular tachycardia

Adenosine compared with calcium channel antagonists for supraventricular tachycardia

Patient or population: patients with supraventricular tachycardia

Setting: emergency department

Intervention: adenosine

Comparison: calcium channel antagonists (CCAs)

\begin{tabular}{|c|c|c|c|c|c|c|c|c|c|}
\hline \multirow[t]{2}{*}{ Outcomes } & \multirow{2}{*}{$\begin{array}{l}\text { Number } \\
\text { of } \\
\text { partici- } \\
\text { pants }\end{array}$} & \multirow{2}{*}{$\begin{array}{l}\text { Number } \\
\text { of stud- } \\
\text { ies }\end{array}$} & \multirow{2}{*}{$\begin{array}{l}\text { Odds ratio } \\
(95 \% \mathrm{Cl})\end{array}$} & \multicolumn{3}{|c|}{ Absolute effects ( $95 \% \mathrm{Cl})$} & \multirow[t]{2}{*}{ Follow-up } & \multirow{2}{*}{$\begin{array}{l}\text { Quality } \\
\text { of the evi- } \\
\text { dence } \\
\text { (GRADE) }\end{array}$} & \multirow[t]{2}{*}{ What happens } \\
\hline & & & & $\begin{array}{l}\text { With } \\
\text { adeno- } \\
\text { sine }\end{array}$ & $\begin{array}{l}\text { With } \\
\text { CCA }\end{array}$ & Difference & & & \\
\hline Odds of reversion & 622 & 7 RCTs & $\begin{array}{l}\text { OR } 1.51 \\
(0.85 \text { to } \\
2.68)\end{array}$ & $89.7 \%$ & $\begin{array}{l}92.9 \% \\
(88.1 \text { to } \\
95.9\end{array}$ & $\begin{array}{l}3.2 \% \text { lower odds } \\
\text { of reversion with } \\
\text { adenosine } \\
\text { ( } 95 \% \mathrm{Cl} 1.2 \text { lower } \\
\text { to } 6.2 \text { lower) }\end{array}$ & $\begin{array}{l}\text { Until reversion oc- } \\
\text { curred } \\
\text { or predetermined } \\
\text { maximum dose was } \\
\text { reached }\end{array}$ & $\begin{array}{l}\oplus \oplus \oplus \Theta \\
\text { MODER- } \\
\text { ATE } a\end{array}$ & $\begin{array}{l}\text { Higher odds of rever- } \\
\text { sion indicate better ef- } \\
\text { fect. }\end{array}$ \\
\hline $\begin{array}{l}\text { Major adverse event: } \\
\text { hypotension }\end{array}$ & 306 & $3 \mathrm{RCTS}$ & $\begin{array}{l}\text { OR } 3.09 \\
(0.12 \text { to } \\
76.71)\end{array}$ & $0.0 \%$ & $\begin{array}{l}0.0 \% \\
(0.0 \text { to } \\
0.0)\end{array}$ & $\begin{array}{l}0.0 \% \text { fewer } \\
\text { (0 fewer to } 0 \text { few- } \\
\text { er) }\end{array}$ & $\begin{array}{l}\text { Up to } 2 \text { hours after } \\
\text { infusion }\end{array}$ & $\begin{array}{l}\oplus \oplus \Theta \odot \\
\text { LOWa,b }\end{array}$ & $\begin{array}{l}\text { Lower hypotension } \\
\text { rate indicates fewer } \\
\text { adverse events. }\end{array}$ \\
\hline $\begin{array}{l}\text { Length of stay in hos- } \\
\text { pital }\end{array}$ & $\begin{array}{l}\text { Not re- } \\
\text { ported }\end{array}$ & 0 & & & & & & & \\
\hline
\end{tabular}

$\mathrm{Cl}$ : confidence interval; OR: odds ratio.

\section{GRADE Working Group grades of evidence}

High quality: We are very confident that the true effect lies close to that of the estimate of the effect.

Moderate quality: We are moderately confident in the effect estimate: The true effect is likely to be close to the estimate of the effect, but there is a possibility that it is substantially different.

Low quality: Our confidence in the effect estimate is limited: The true effect may be substantially different from the estimate of the effect,

Very low quality: We have very little confidence in the effect estimate: The true effect is likely to be substantially different from the estimate of effect.

$\omega \quad$ aQuality of the evidence downgraded by one level for imprecision. Moderate to wide confidence intervals. 


\section{B A C K G R O U N D}

\section{Description of the condition}

\section{Definitions}

Supraventricular tachycardia (SVT) includes all tachyarrhythmias that originate in supraventricular tissue or incorporate supraventricular tissue in the re-entrant circuit and have sudden onset and termination. Atrioventricular nodal re-entrant tachycardia (AVNRT) and atrioventricular re-entrant tachycardia (AVRT) (such as Wolff-Parkinson-White syndrome) are two major types of SVT; other types include atrial tachycardia, paroxysmal atrial flutter, and paroxysmal atrial fibrillation (Jayam 2004). Most patients with SVT due to AVNRT or AVRT do not have associated structural heart disease (Ferguson 2003).

\section{Epidemiology}

SVT is a common arrhythmia with a prevalence of 2 per 1000 adults. The incidence of SVT is 36 per 100,000 people per year, and women have twice the risk of developing SVT compared with men (Orejarena 1998).

\section{Clinical presentation and diagnosis}

SVTs are often recurrent and occasionally persistent, and are a frequent cause of visits to emergency departments and primary care physicians' offices. Common symptoms of SVT include palpitations, anxiety, light-headedness, chest pain, neck pounding, and dyspnoea (Delacrétaz 2006; Medi 2009). For patients presenting with SVT, a 12-lead electrocardiogram (ECG) that shows a narrow complex tachycardia is essential for making the diagnosis and may reveal the mechanism of the arrhythmia.

\section{Treatment}

Treatment in stable, symptomatic patients is aimed at terminating the rhythm by decreasing conduction through the atrioventricular (AV) node. Increasing vagal tone by the Valsalva manoeuvre or by carotid sinus massage will effectively revert up to $53 \%$ of patients to sinus rhythm (Wen 1998). A modified Valsalva manoeuvre with leg elevation and supine positioning can further improve success (Appelboam 2015). A recent Cochrane review assessed effectiveness of the Valsalva manoeuvre in terminating SVT and showed a reversion success rate between $19.4 \%$ and $54.3 \%$ in two studies. However, evidence was insufficient overall to support its effectiveness in terminating SVT (Smith 2015). For patients in whom vagal manoeuvres are not effective, calcium channel antagonists (CCAs), adenosine, sotalol, beta-blockers, and magnesium sulphate have been shown to be more effective than placebo (Dougherty 1992; Gupta 1999; Jordaens 1991; Joshi 1995). However, for acute management, adenosine and non-dihydropyridine CCAs verapamil and diltiazem - are the intravenous drugs of choice for termination of SVT (Mangrum 2002). The 2015 American Heart Association (AHA) Guidelines for Cardiopulmonary Resuscitation and the 2015 European Resuscitation Council (ERC) Guidelines for Resuscitation for regular narrow complex SVT recommend use of adenosine if vagal manoeuvres have failed to terminate the SVT. CCAs are recommended as a second-line drug if adenosine is contraindicated or fails to terminate the SVT (Page 2016; Soar 2015). The decision as to which agent should be used is generally determined by clinician preference, personal experience, and institutional culture.

\section{Description of the intervention}

Adenosine and CCAs have been widely used in SVT with similar efficacy (Bolton 2000; Delaney 2011). Moreover, the previous version of this Cochrane review, which compared these agents, showed no significant differences in reversion rate between the two drugs (Holdgate 2006). However, adenosine is significantly more costly than most intravenous (IV) CCAs.

Adenosine has a half-life of less than a minute, and reversion to sinus rhythm may be short-lived, as a subsequent ectopic beat may reinitiate SVT. Many patients experience short-lived but unpleasant side effects following administration of adenosine, including dyspnoea, flushing, and, perhaps most dreadfully, a sense of impending death or doom that can be very frightening (Bolton 2000; Katzung 1995). The recommended adult dosage of adenosine for peripheral infusion is $6 \mathrm{mg}$, followed by a 12-mg dose if needed. Because of the ultrashort duration of action, cumulative effects of sequential doses are not seen (Ferguson 2003).

On the other hand, CCAs have been used in SVT for many years and are effective in up to $90 \%$ of patients (Bolton 2000; Delaney 2011). Calcium channel blockade causes negative inotropy and peripheral vasodilation, which may result in hypotension, particularly among patients with impaired left ventricular function. CCAs have a relatively long half-life of three to six hours, thus adverse effects may be prolonged. They are relatively contraindicated in patients who are already taking beta-blockers, as the combined effect may lead to significant bradycardia (Katzung 1995). The recommended dosage of verapamil is $5 \mathrm{mg}$ IV over 2 minutes, followed in 5 to 10 minutes by a second dose of 5 to $7.5 \mathrm{mg}$. The recommended dosage of diltiazem is $20 \mathrm{mg}$, followed, if necessary, by a second dose of 25 to $35 \mathrm{mg}$; SVT termination should occur within 5 minutes of infusion completion (Ferguson 2003).

\section{How the intervention might work}

Both adenosine and CCAs inhibit conduction through the AV node, which facilitates termination of SVT. Adenosine is an endogenous nucleoside that acts by inhibiting cyclic adenosine monophosphate (CAMP)-mediated calcium influx and enhancing potassium conduction. This leads to inhibition of AV nodal conduction and expansion of the AV nodal refractory period. In contrast, CCAs act by blocking voltage-dependent calcium channels, thus reducing intracellular calcium and leading to blockade of calcium-dependent conduction through the AV node (Katzung 1995).

\section{Why it is important to do this review}

The previous version of this review showed that adenosine and CCAs are reasonably effective but have a significant side effect profile (Holdgate 2006). This review update looks at new studies conducted over the past 10 years and aims to further explore uncertainty while helping clinicians and decision makers to regulate the choice between adenosine and CCAs. Recent American and British guidelines recommend adenosine as first pharmacological treatment for stable patients with SVT after vagal manoeuvres are attempted (Blomstrom-Lundqvist 2003; Page 2016; Resuscitation Council (UK) 2015). 


\section{OB JECTIVES}

To review all randomised controlled trials (RCTs) that compare effects of adenosine versus CCAs in terminating SVT.

\section{ME T HODS}

\section{Criteria for considering studies for this review}

\section{Types of studies}

We planned to include RCTs. We excluded studies reported to be randomised but exhibiting major violations in randomisation methods or treatment allocation, or major differences in baseline characteristics unlikely to have occurred by chance (Athar 2013; Riaz 2012). We contacted authors of studies with protocol violations or for whom we had questions regarding the randomisation process or approval. We excluded these studies from the analysis until we receive further information.

\section{Types of participants}

We included patients of any age with SVT diagnosed on 12-lead ECG within 24 hours of onset.

We excluded RCTs of patients with an SVT induced in the electrophysiology lab, as they do not meet the aim of this review, which focuses on SVT (see Differences between protocol and review section)

\section{Types of interventions}

We included all interventions that directly compare any intravenous CCA (e.g. verapamil, diltiazem) versus IV adenosine, at any dosage or infusion rate of either drug.

\section{Types of outcome measures}

\section{Primary outcomes}

1. Reversion to sinus rhythm

2. Major adverse events (defined as cardiac arrest, prolonged hypotension, symptomatic bradycardia requiring treatment, and acute cardiac failure)

\section{Secondary outcomes}

1. Time to immediate reversion to sinus rhythm

2. Rate of relapse to SVT within two hours following reversion

3. Length of stay in hospital

4. Minor adverse events (defined as any reported adverse events other than those defined above)

5. Patient satisfaction as measured on any validated scale

\section{Search methods for identification of studies}

\section{Electronic searches}

We updated searches conducted in 2006 for the original review (Appendix 1) by searching the following databases on 5 July 2017 for relevant RCTs (Appendix 2).

1. Cochrane Central Register of Controlled Trials (CENTRAL), in the Cochrane Library (2017; Issue 6 of 12).

2. Epub Ahead of Print, In-Process \& Other Non-Indexed Citations, MEDLINE Daily, and MEDLINE (Ovid, 1946 to 5 July 2017).

\section{Embase (Ovid, 1980 to 2017 Week 27).}

We applied the sensitivity-maximising version of the Cochrane RCT filter to our MEDLINE search, and we applied terms as recommended in the Cochrane Handbook for Systematic Reviews of Interventions to our Embase search (Lefebvre 2011). We imposed no restrictions on date or language of publication.

\section{Searching other resources}

We searched the following sources.

1. Reference lists of relevant identified publications.

2. Two databases of ongoing trials- ClinicalTrials.gov (www.clinicaltrials.gov) and the World Health Organization (WHO) International Clinical Trials Registry Platform (ICTRP) (apps.who.int/trialsearch/) - on 7 July 2017 (Appendix 2).

\section{Data collection and analysis}

\section{Selection of studies}

Two review authors (MQ and AS) independently screened titles and abstracts for inclusion of all eligible studies identified as a result of the search and coded them as 'retrieve' (eligible or potentially eligible/unclear) or 'do not retrieve'. For disagreements, we asked a third review author (SA) to arbitrate. We retrieved full-text study reports/publications; two review authors (MQ and AS) independently screened the full texts and identified studies for inclusion, or recorded reasons for exclusion of ineligible studies. We resolved disagreements through discussion or through consultation with a third review author (SA). We identified and excluded duplicates and collated multiple reports of the same study, so that each study rather than each report was the unit of interest in the review. We recorded the selection process in sufficient detail and completed a PRISMA flow diagram and Characteristics of excluded studies tables.

We excluded all publications that were reviews, retrospective studies, or studies of observational design, as well as those that were not randomised, or did not focus on adenosine or CCAs or SVT.

\section{Data extraction and management}

Four review authors (MQ, AS, EA, and TJAC) extracted data for the eligible studies so that each eligible study was independently extracted by two authors. We extracted and collated data using a standardised, agreed upon data extraction form. Data collected include:

1. general information: publication type; title, authors, source, country, year of publication, trial dates, additional publications;

2. trial characteristics: design, setting, duration, types of interventions, types of outcome measures, aim of study, randomisation (and method), allocation concealment (and method), blinding (outcome assessors), check of blinding, funding/conflict of interest;

3. participants: unit of allocation, method of recruitment, inclusion criteria, exclusion criteria, total number and numbers in comparison groups, sex/age, ethnicity, severity of illness, subgroups reported, similarity of groups at baseline, withdrawals/losses to follow-up; 
4. intervention: dosage, delivery, timing, administration rate, type of CCA, length of intervention, co-interventions, costs, compliance;

5. outcomes: outcomes as specified above, the main outcome assessed in the study, other events, length of follow-up; and

6. results: for outcomes assessed.

\section{'Summary of findings' table}

We used the GRADE approach, adopted by Cochrane, to interpret findings (Schünemann 2011). We used the GRADE profiler website (www.gradepro.org) to create a 'Summary of findings' table. Two review authors (SA, AS) independently assessed the quality of included studies.

With GRADEproGDT (GRADEproGDT 2015), evidence relative to each specific outcome is rated as having high, moderate, low, or very low quality. We started rating outcomes of all randomised trials as high quality and downgraded them depending on limitations in study design or execution, indirectness of evidence, unexplained heterogeneity, imprecision of results, and high probability of publication bias. By using GRADEproGDT, we produced a 'Summary of findings' table to show outcome-specific ratings and to present information about the overall quality of evidence.

We selected all primary outcomes for inclusion in the 'Summary of findings' table. In addition, we had planned to include length of stay in hospital and patient experience as patient-relevant outcomes, but included studies did not report this information.

\section{Assessment of risk of bias in included studies}

For this updated review, two review authors (MQ, AS, EA, and TJAC) independently carried out risk of bias assessment.

We assessed risk of bias of included trials, using the methods detailed in Chapter 8 of the Cochrane Handbook for Systematic Reviews of Interventions (Higgins 2011). We rated the risk of selection bias by assessing randomisation and allocation concealment. We rated performance, detection, and attrition bias by assessing blinding to treatment, blinding to outcome assessment, and losses to follow-up. We planned to assess selective reporting bias by cross-checking study outcomes against published protocols or trial registrations.

We coded each risk of bias criterion as having high risk, low risk, or unclear risk of bias, and we resolved disagreements by discussion. When necessary, we contacted study authors to try to clarify trial methods.

\section{Measures of treatment effect}

We followed the recommendations provided in the Cochrane Handbook for Systematic Reviews of Interventions, Sections 9.2 and 9.4, for measuring effects of different data types (Higgins 2011). For continuous outcomes (e.g. time to reversion), we calculated mean differences (MDs) and 95\% confidence intervals (Cls), and for dichotomous outcomes (e.g. odds of reversion, adverse events), we calculated odds ratios (ORs) and $95 \% \mathrm{Cls}$.

\section{Unit of analysis issues}

Our unit of analysis was the participant. For cross-over trials, we included only data from the pre-cross-over phase, as time between drugs was short and did not allow drug washout. We did not encounter any cluster-randomised trials.

\section{Dealing with missing data}

When possible, we extracted data relevant to intention-to-treat analyses.

\section{Assessment of heterogeneity}

We analysed statistical heterogeneity by visually inspecting the forest plot and carrying out both $\mathrm{Chi}^{2}$ and $\mathrm{I}^{2}$ tests, as recommended in Chapter 9.5.2 of the Cochrane Handbook for Systematic Reviews of Interventions (Higgins 2011). For the $\mathrm{Chi}^{2}$ test on $\mathrm{N}-1$ degrees of freedom, we defined $\mathrm{P}<0.1$ as showing substantial heterogeneity. We used the $1^{2}$ statistic to quantify statistical inconsistency and to assess the impact of heterogeneity on the meta-analysis. We determined that $12>50 \%$ demonstrated high heterogeneity.

If no heterogeneity was present, we performed analysis using a fixed-effect model. When we detected substantial heterogeneity, we investigated possible sources of heterogeneity (e.g. study quality, outcome measures, participants, interventions). When the source of heterogeneity could not be explained, we did not combine study results.

\section{Assessment of reporting biases}

To assess the risk of publication bias, we had planned to construct funnel plots for each outcome with at least 10 trials; however, this was not possible owing to the limited number of included studies (Sterne 2011).

\section{Data synthesis}

We used Review Manager 5 software to perform data analysis (RevMan 5.3).

\section{Subgroup analysis and investigation of heterogeneity}

We planned subgroup analysis based on participant age, gender, duration of symptoms, intercurrent drug therapy, presence of underlying heart disease, prior treatments, and drug dosage to explore different effects amongst different groups. However, we found insufficient data to carry out these subgroup analyses.

\section{Sensitivity analysis}

We had planned to conduct sensitivity analyses on the primary outcomes to re-analyse exclusion of studies that we judged to be at high risk of bias across one or more domains of the Cochrane 'Risk of bias' tool. This was not possible, as all included studies had at least one domain with high risk of bias.

\section{RE S U L T S}

\section{Description of studies}

\section{Results of the search}

We identified 237 new references in our updated literature review. We screened 192 records on the basis of title and abstract after removing duplicates. We excluded most studies on abstract review because they were not RCTs or did not compare adenosine versus a CCA. We assessed eight full-text records and included two studies (Lim 2009; Vranic 2006). Figure 1 shows a flow chart of the updated search. 


\section{Figure 1. Study flow diagram.}

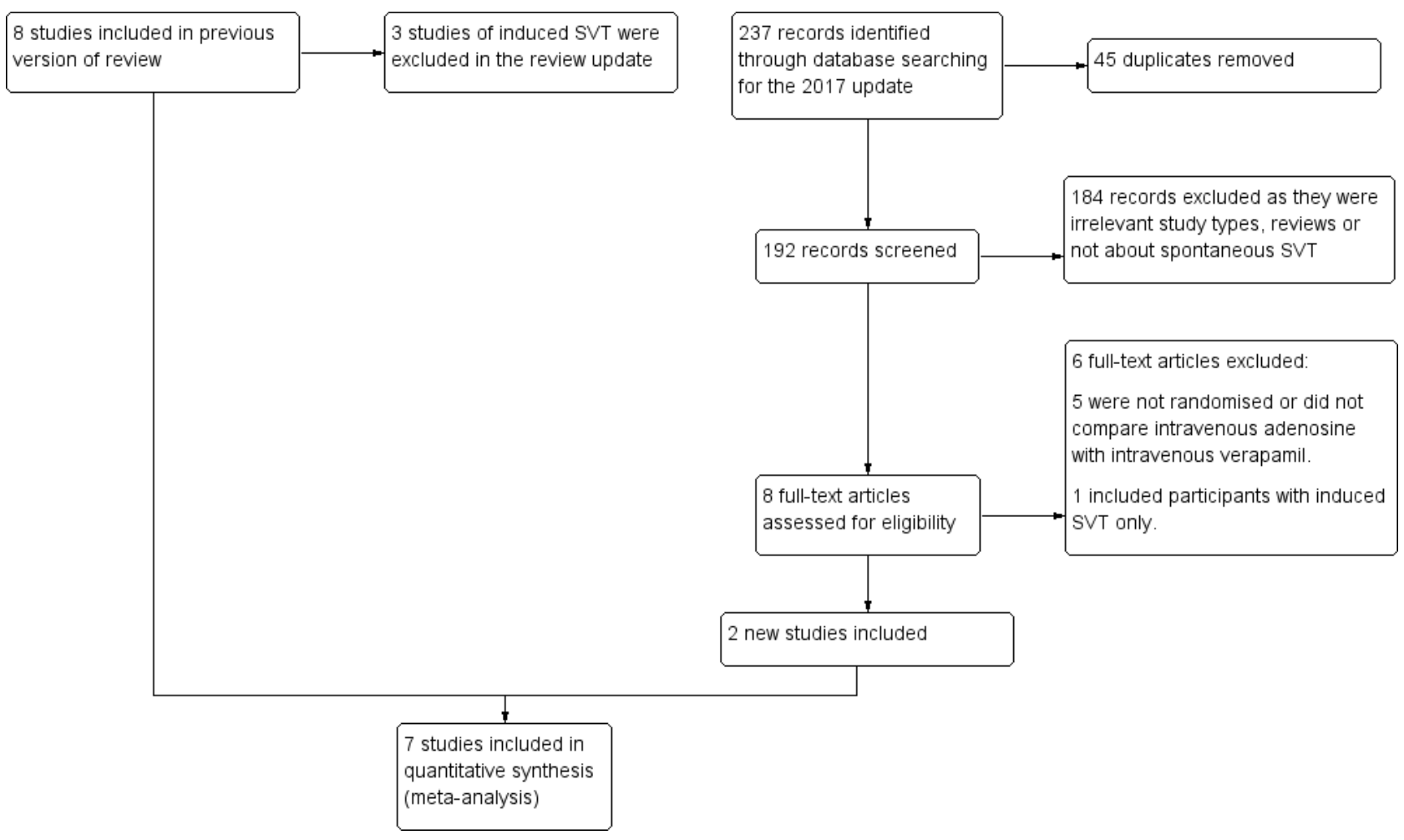

We found no trials from reference checking and no ongoing trials upon searching ClinicalTrials.gov and the International Clinical Trials Registry Platform.

The original review included eight trials (Cabrera-Sole 1989; Cheng 2003; DiMarco 1990; Ferreira 1996; Gil Madre 1995; Greco 1982; Hood 1992; Kulakowski 1998). In this updated review, we excluded three of these, as they included patients with induced SVT (DiMarco 1990; Hood 1992; Kulakowski 1998). See Differences between protocol and review for clarification.

\section{Included studies}

\section{Study designs}

Four studies included a cross-over component in which the alternate study drug was administered if the first drug was unsuccessful (Lim 2009; Ferreira 1996; Gil Madre 1995; Greco 1982). The authors of one study did not report results after cross-over but counted them as showing failure of the initial treatment intervention (Lim 2009). Otherwise, we included only data from the pre-cross-over phase, as time between drugs was short and did not allow drug washout (particularly for verapamil). Another study included a third treatment arm given digitalis and did not provide data from this component of the trial (Greco 1982). The Lim trial,divided the CCA arm into verapamil and diltiazem (Lim 2009). We combined these arms in a single CCA group for the purposes of our meta-analysis.

The other three included studies reported that they were randomised and provided no further explanation (Cabrera-Sole 1989; Cheng 2003; Vranic 2006).
None of the included studies attempted blinding of participants or personnel.

Study design characteristics of the included studies can be found in the Characteristics of included studies tables.

\section{Participants}

The seven included trials were conducted in six different countries, were published between 1982 and 2009, and included 622 participants (Cabrera-Sole 1989; Cheng 2003; Ferreira 1996; Gil Madre 1995; Greco 1982; Lim 2009; Vranic 2006). All studies but one were conducted in adults (Greco 1982). Inclusion criteria for one trial included people above the age of 10 . However, it was not possible to determine how many children younger than 18 were included in this trial (Lim 2009).

All included studies enrolled patients with SVT only.

\section{Interventions}

Four trials used adenosine in the form of ATP (adenosine triphosphate) (Cabrera-Sole 1989; Ferreira 1996; Gil Madre 1995; Greco 1982); the remaining five used adenosine. ATP is rapidly converted to adenosine (the free base form) following exogenous administration; $10 \mathrm{mg}$ ATP is equipotent to $6 \mathrm{mg}$ adenosine, and a linear dosage relationship has been noted between these two forms of the drug (Belhassen 1984; Faulds 1991). Verapamil was the CCA used in all trials. One trial included an arm of diltiazem that was analysed with verapamil in a combined CCA group (Lim 2009). One trial administered adenosine in doubling doses (3 mg-6 mg-12 mg), and another used dosing starting at $10 \mathrm{mg}$ ATP (equivalent to $6 \mathrm{mg}$ adenosine) followed by $20 \mathrm{mg}$ ATP (Cheng 2003; Ferreira 1996). Two 
trials gave adenosine $6 \mathrm{mg}$ IV bolus followed by $12 \mathrm{mg}$ IV bolus if SVT was not reverted with the first bolus (Lim 2009; Vranic 2006).

Cheng 2003, Ferreira 1996, and Gil Madre 1995 gave verapamil in 5-mg boluses. Cheng 2003 gave a 5-mg verapamil infusion over five minutes, Gil Madre 1995 in three minutes, Riaz 2012a in two minutes, and Ferreira 1996 in one minute. One trial did not specify whether the 5-mg verapamil bolus was infused over time or was given as an injection (Vranic 2006).

Verapamil was given at a fixed dose of $10 \mathrm{mg}$ in Cabrera-Sole 1989. Another trial administered adenosine by slow intravenous infusion at a rate of $1 \mathrm{mg}$ per minute up to a maximum dose of $20 \mathrm{mg}$ while assessing the rhythm every two minutes (Lim 2009).

One trial administered diltiazem by slow intravenous infusion at a rate of $2.5 \mathrm{mg}$ per minute up to a maximum dose of $50 \mathrm{mg}$, while assessing the rhythm every two minutes (Lim 2009).

\section{Outcomes}

All trials reported reversion to sinus rhythm as the main outcome. Researchers reported continuous ECG monitoring or ECG recording in Cheng 2003, Gil Madre 1995, Greco 1982, and Vranic 2006. Infusions were given until successful conversion to sinus rhythm occurred without further details on how this was assessed in Cabrera-Sole 1989, Ferreira 1996, and Lim 2009. Investigtors in all included studies monitored heart rate and blood pressure throughout infusion.

No studies reported length of stay in hospital nor outcomes derived from patient satisfaction surveys.

\section{Excluded studies}

We excluded five studies after acquiring full texts (Athar 2013; Gill 2014; Riaz 2012; Shaker 2015; Turkoglu 2009).

Riaz 2012 mentions randomisation only in the title and provides no further explanation in the Methods section. We contacted study authors for further clarification. This study mentions that a lottery method was used as the allocation method without providing further explanation about what this involved. When contacted, study authors described potentially significant differences in baseline characteristics (four-year difference in age and no $\mathrm{P}$ for comparison) and explained that no other baseline comparisons were available). We deemed that this trial did not use an appropriate randomisation method and therefore excluded it from this review.

Athar 2013 reports a quasi-experimental trial, with participants "randomly" allocated to two groups. However, study authors did not conceal allocation, as randomised participants received the alternate study drug (rather than the allocated drug) if they had a personal preference for the other drug owing to previous exposure. This article makes no further mention and provides no details of randomisation; multiple attempts to contact study authors were met with no response for clarification.

Gill 2014 makes no mention of randomisation; our attempts to contact study authors for clarification resulted in no response. Shaker 2015 was an RCT that compared IV adenosine versus IV adenosine and oral verapamil. Turkoglu 2009 enrolled only participants with induced SVT.

We excluded three studies that were initially included in the original review, as they enrolled patients with induced SVT (DiMarco 1990; Hood 1992; Kulakowski 1998). See Differences between protocol and review for clarification.

We have provided study design characteristics of all excluded studies in the Characteristics of excluded studies tables.

\section{Risk of bias in included studies}

For details on risk of bias in included studies, see 'Risk of bias' tables (Characteristics of included studies). We have presented information on overall risk of bias in Figure 2 and Figure 3.

\section{Figure 2. Risk of bias graph: review authors' judgements about each risk of bias item presented as percentages} across all included studies.

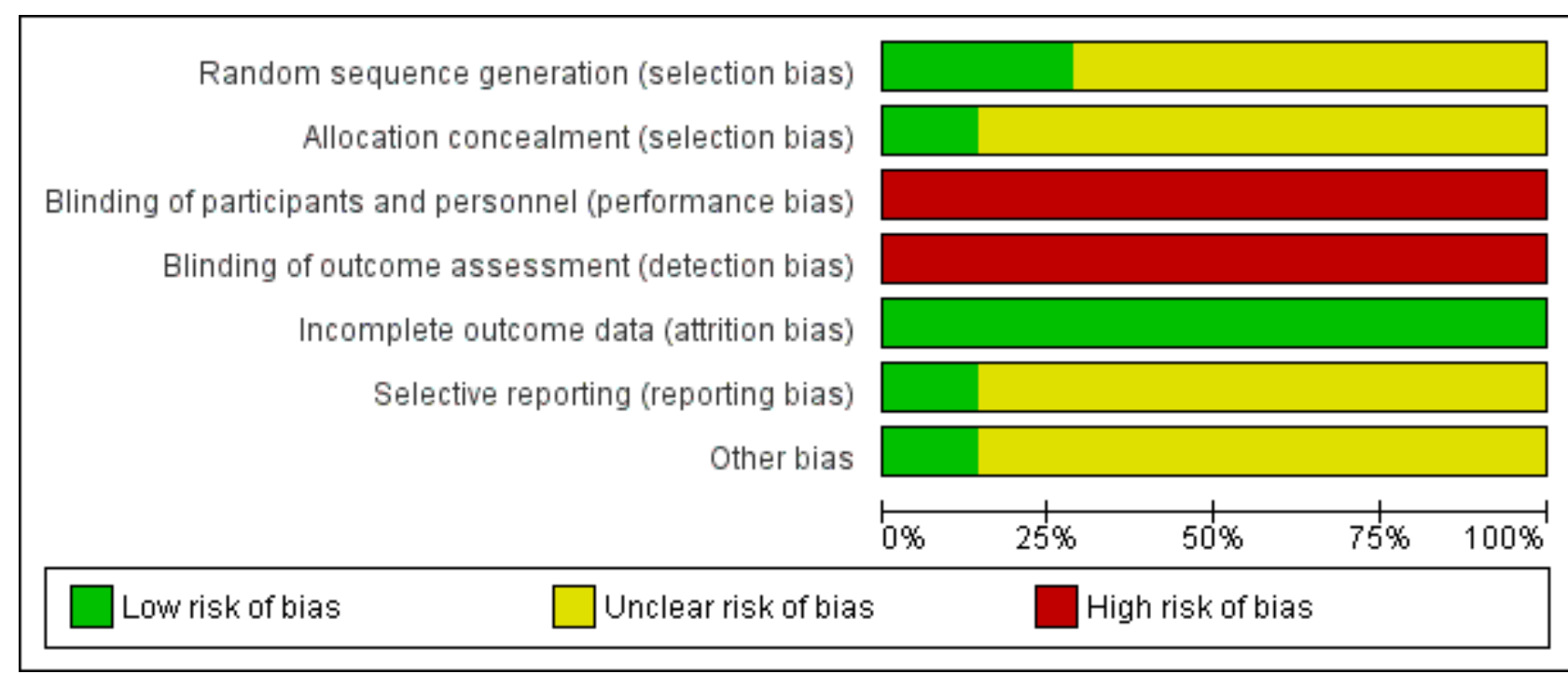


Figure 3. Risk of bias summary: review authors' judgements about each risk of bias item for each included study.

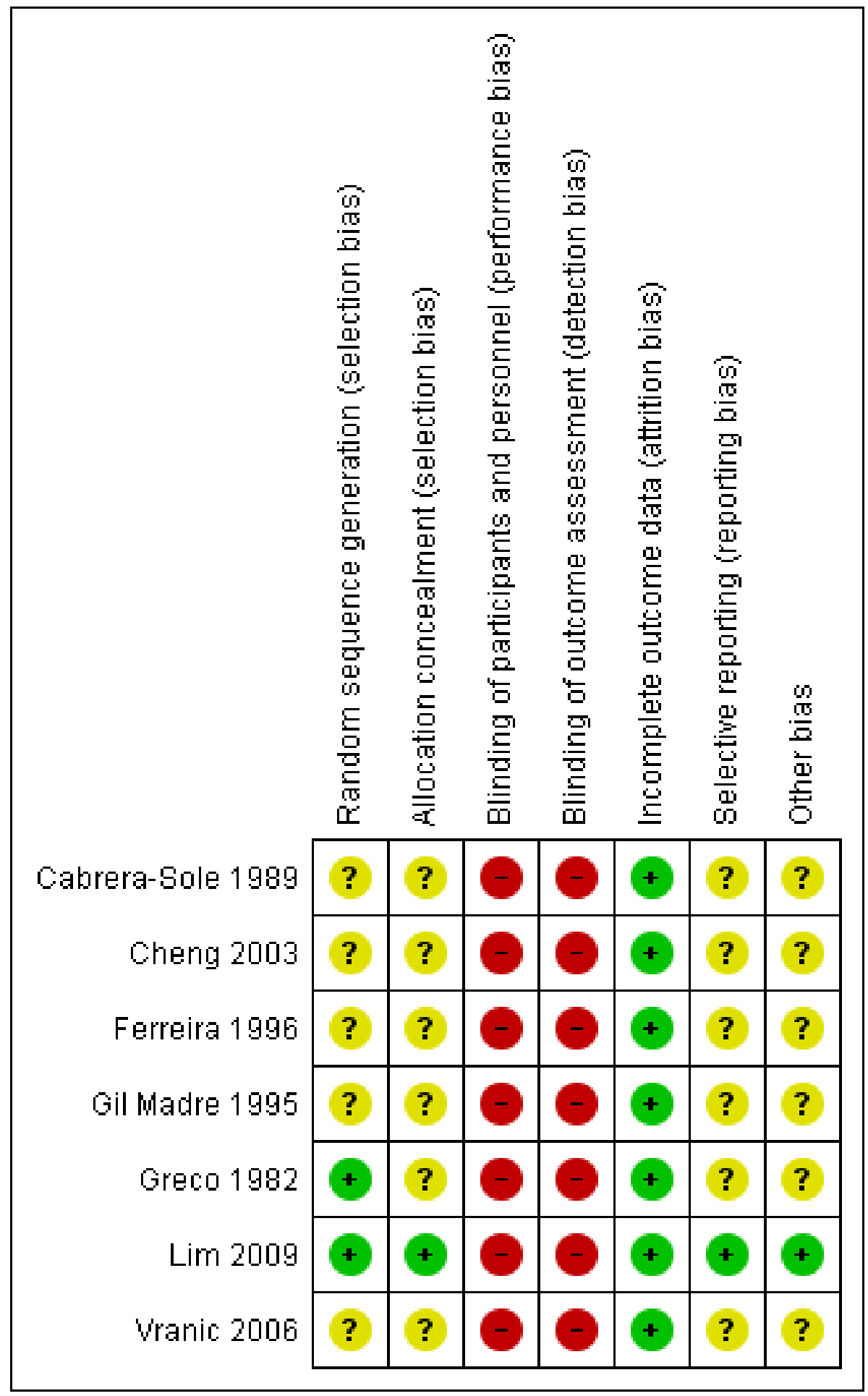

\section{Allocation}

\section{Random sequence generation}

Two trials described the randomisation process (Greco 1982; Lim 2009). Investigators used a random numbers table to allocate participants to treatment in Greco 1982. A nurse drawing a serialised sealed envelope performed randomisation In Lim 2009.
All included studies provided data showing that participants in both drug groups were of similar age and had similar physiological parameters at the time of enrolment.

Adenosine versus intravenous calcium channel antagonists for supraventricular tachycardia (Review) 


\section{Allocation concealment}

Only one trial reported adequate allocation concealment using an envelope method (Lim 2009). The remaining six trials did not provide sufficient information to reveal whether allocation concealment was adequate.

\section{Blinding}

We rated blinding as introducing high risk of bias in all included studies, as none reported blinding of participants, caregivers, outcome assessors, or investigators. As these two drugs are usually given by different methods (adenosine as a rapid bolus, and CCAs as a slower IV infusion), it would be possible to achieve blinding only by using a double-dummy method, which would require substantial resources. However, no investigators discussed this issue.

\section{Incomplete outcome data}

Trialists applied all interventions and assessed all outcomes in the emergency department during admission of patients. All studies reported outcomes for all included patients and reported no withdrawals or dropouts; therefore we rated risk of attrition bias as low for all studies.

\section{Selective reporting}

No protocols for included studies were available for crosschecking of reported study outcomes versus published protocols. All included trials described outcomes in the Methods sections.

We found a prospective trial registration in clinicaltrials.gov for Lim 2009. Planned outcomes included conversion to sinus rhythm as a primary outcome, and recurrence of SVT and vital signs as secondary outcomes. Trial authors reported these outcomes in the published article.

\section{Other potential sources of bias}

\section{Inclusion and exclusion criteria}

All trials described inclusion criteria, although most studies stated that a diagnosis of SVT was the main inclusion criterion without defining SVT by rate or QRS width, and provided no time limit on duration of symptoms. All but one study described exclusion criteria well (Cabrera-Sole 1989).

\section{Publication bias}

A funnel plot was not appropriate for assessment of publication bias, as this review includes fewer than 10 studies (Sterne 2011).

\section{Conflicts of interest and funding}

Only one study included a declaration of interests and reported its source of financial support (Lim 2009). Trial authors reported the absence of any conflicts of interests and receipt of funding from the Department of Clinical Research of Singapore General Hospital for costs of adenosine and diltiazem.

\section{Effects of interventions}

See: Summary of findings for the main comparison Adenosine compared with calcium channel antagonists for supraventricular tachycardia

\section{Odds of reversion}

All seven studies reported odds of reversion or 'efficacy' of adenosine versus CCA as an outcome measure, noting no difference in the odds of reversion to sinus rhythm among participants treated with adenosine or CCA (Analysis 1.1: 89.7\% vs 92.9\%; odds ratio (OR) $1.51,95 \%$ confidence interval $(\mathrm{Cl}) 0.85$ to 2.68 ; participants $=622$; studies $\left.=7 ;\left.\right|^{2}=36 \%\right)$. This result is based on evidence of moderate quality (Summary of findings for the main comparison).

Low heterogeneity between trials can be explained by differences in doses of adenosine and verapamil given. All but one study used sequentially increasing doses of each trial drug until reversion occurred or the predetermined maximum dose was reached, whichever occurred first (Cabrera-Sole 1989). Six trials reported odds of reversion as overall cumulative reversion for participants who received one or more doses of each drug. Trialists in one study used a fixed dose of each drug with no escalation of drug dosage in the absence of reversion (Cabrera-Sole 1989).

\section{Major adverse events}

Three trials reported outcomes of hypotension, noting only one episode of hypotension with CCA and none with adenosine (Analysis 1.5: $0.66 \%$ vs $0 \%$; OR $3.09,95 \% \mathrm{Cl} 0.12$ to 76.71 ; participants $=306$; studies $\left.=3 ; 1^{2}=0 \%\right)$ (Cabrera-Sole 1989; Ferreira 1996; Lim 2009). This result is not precise, and the confidence interval is wide. These results are based on evidence of low quality (Summary of findings for the main comparison).

Two of the three trials reporting hypotension specifically excluded patients with systolic blood pressure (BP) $<90 \mathrm{mmHg}$ at enrolment. A hypotensive episode in one trial occurred at infusion of $7.5 \mathrm{mg}$ of verapamil and did not require specific treatment (Lim 2009).

Only one study specifically reported absence of major bradycardia in either group (Ferreira 1996). No studies reported acute heart failure.

The only paediatric study reported that two participants experienced cardiac arrest after receiving treatment with verapamil (Greco 1982). One was an infant with cyanotic heart disease and electrolyte disturbances, the other was an infant already receiving treatment with a beta-blocker for Wolff-Parkinson-White syndrome. Both children were successfully resuscitated.

\section{Time to reversion}

Average time to reversion was reported in four studies (Cheng 2003; Ferreira 1996; Lim 2009; Vranic 2006). Each study showed a statistically significantly shorter time to reversion with adenosine than with verapamil. Average time to reversion in all studies combined was 44 seconds for adenosine and 394 seconds for CCAs. Very high heterogeneity between studies made pooling of results inappropriate. This heterogeneity may be due to differences in timing and dosing protocols between trials. Cheng 2003 reported 'average time after dose'; trialists did not report how time to reversion was estimated in two trials (Lim 2009; Vranic 2006).

\section{Relapse rate}

Four studies reported rate of relapse to SVT following reversion to sinus rhythm (Ferreira 1996; Gil Madre 1995; Lim 2009; Vranic 2006). Results show no differences in relapse rates between adenosine and CCAs (Analysis 1.3: 3.3\% vs $1.14 \%$; OR $0.38,95 \% \mathrm{Cl} 0.09$ to 
1.69; participants $=358 ;$ studies $\left.=4 ; 1^{2}=0 \%\right)$. Two studies reported the period of observation following drug administration as 2 hours and 24 hours, respectively (Lim 2009; Vranic 2006). Ferreira 1996 reported relapse at 10 minutes for one participant given adenosine but did not mention time to relapse for the other participant given verapamil.

\section{Length of stay in hospital}

None of the included studies reported this outcome.

\section{Minor adverse events}

Studies reported numbers of specific adverse events rather than numbers of participants experiencing minor adverse events. Reported minor adverse events included chest tightness, nausea, shortness of breath, headache, and flushing. As patients might experience several different minor adverse events, double counting and exaggeration of estimated effects may occur. Therefore, we have not provided a total pooled estimate of minor adverse event subgroups.

Three trials reported that chest tightness occurred more frequently among participants treated with adenosine compared with verapamil (Analysis 1.4.1: $11.7 \%$ vs $0 \%$; OR $0.09,95 \% \mathrm{Cl} 0.02$ to 0.50 ; participants $=222$; studies $=3 ; 12=0 \%)($ Cheng 2003; Ferreira 1996; Gil Madre 1995).

Two trials reported shortness of breath, noting no differences between adenosine and CCAs (Analysis 1.4.2: $6.9 \%$ vs $1.2 \%$; OR $0.23,95 \% \mathrm{Cl} 0.04$ to 1.37 ; participants $=171$; studies $\left.=2 ;\left.\right|^{2}=0 \%\right)$ (Cheng 2003; Gil Madre 1995). These trials also reported nausea and headache, but high heterogeneity for these outcomes made pooling of results inappropriate.

Flushing as reported in trial was higher in the adenosine group (Analysis 1.4.3: $61.5 \%$ vs $0 \%$; OR $0.01,95 \% \mathrm{Cl} 0.00$ to 0.24 ; participants $=50 ;$ studies $\left.=1 ;\left.\right|^{2}=0 \%\right)($ Gil Madre 1995) .

Greco 1982 also reported nausea, chest tightness, shortness of breath, and headache at higher rates among participants treated with adenosine. However, data included results from a nonrandomised component of the study; therefore, we did not include these outcomes in the pooled analysis.

Two trials did not report any minor adverse events (Lim 2009; Vranic 2006).

\section{Patient satisfaction}

None of the included studies reported this outcome.

\section{Subgroup analysis}

We found insufficient data to carry out intended subgroup analyses.

\section{Sensitivity analysis}

All included studies had one or more component at high risk of bias; therefore, a sensitivity analysis for studies with low risk of bias was not possible.

\section{DISCUSSION}

\section{Summary of main results}

\section{Adenosine and CCA efficiency}

Our review aimed to examine the relative efficacy and safety of adenosine and calcium channel antagonists (CCAs) for patients presenting with supraventricular tachycardia (SVT). We included seven trials with 622 participants.

We used three outcomes to compare efficiency of these agents: odds of reversion, time to reversion, and relapse rates. Reversion and relapse rates were similar with adenosine and CCAs. We could not reliably examine time to reversion in a pooled analysis owing to severe heterogeneity. Time to reversion was on average less than a minute with adenosine and longer than six minutes with CCAs. The difference between these two treatments is probably of little clinical significance for patients who are haemodynamically stable.

\section{Adverse effects}

Investigators reported only one episode of hypotension among patients treated with verapamil and none in those treated with adenosine. Two cardiac arrests occurred in a paediatric study published in the 1980s, in clinical circumstances for which current practice guidelines would not recommend verapamil without expert consultation (ACLS 2015).

Minor adverse events occurred more frequently with adenosine and affected approximately one in ten patients. No studies specifically defined minor adverse events. Study authors relied on post hoc reporting; therefore, it is possible that the actual rate was higher than was reflected in the data. From a medical perspective, shortlived symptoms such as chest pain may be perceived as minor; however, no studies explored patients' perception of the relative severity of these events. No study commented on the sense of impending death or doom associated with adenosine treatment.

\section{Patient-centred outcomes}

The two outcomes for which we could find no data (i.e. patient satisfaction and length of hospital stay) may be helpful in the clinical decision as to which treatment should be used. From the patient's perspective, the risk of brief but unpleasant side effects, such as feeling close to death, may be unacceptable.

\section{Overall completeness and applicability of evidence}

The main gap in current knowledge involves patient preference. None of the included studies reported results on patient experiences.

\section{Quality of the evidence}

The GRADE approach shows that the quality of the evidence is moderate for the odds of reversion outcome (i.e. the result is likely to be close to the true effect but can be substantially different). The quality of evidence is low for the outcome of rate of major adverse events, but this result should be viewed with caution (Summary of findings for the main comparison). Reasons for downgrading the quality of evidence for adverse events were the presence of high risk of bias in the blinding domain for all included studies and imprecision of results with wide confidence intervals. As studies objectively assessed reversion to sinus rhythm using electrocardiograms (ECGs), lack of blinding of participants 
or outcome assessors is not expected to have an impact on this endpoint.

Authors of all seven included studies stated that these were randomised trials; however, randomisation was poorly or incompletely reported. Only two studies specified how randomisation was undertaken (Greco 1982; Lim 2009). One study described allocation concealment (Lim 2009). None of the included studies were blinded. Most included trials used a cross-over design; however we have provided only pre-cross-over data in this review.

\section{Potential biases in the review process}

We performed a comprehensive literature search to find all relevant trials for inclusion in this review. Two review authors independently performed the literature search, selected studies, extracted data, and assessed risk of bias to minimise review bias. We contacted study authors to request further information when needed.

We conducted the review according to the previously published protocol. However, in some ways, we deviated from the protocol during the review process. We have documented deviations under Differences between protocol and review.

\section{Agreements and disagreements with other studies or reviews}

Delaney 2011 is a systematic review and meta-analysis of adenosine versus verapamil for treatment of stable SVT. This review included eight studies (Cabrera-Sole 1989; Cheng 2003; DiMarco 1990; Ferreira 1996; Gil Madre 1995; Hood 1992; Kulakowski 1998; Lim 2009). Review authors concluded that both adenosine and verapamil are effective and safe and included studies with induced SVT that we excluded from our review.

\section{AUTHORS' CONCLUSIONS}

\section{Implications for practice}

\section{For people with SVT}

We found no evidence of differences in effects of adenosine and calcium channel antagonists (CCAs) for treatment of supraventricular tachycardia (SVT). Our results are based on evidence of moderate quality. We found that adenosine is associated with more frequent minor adverse events such as chest pain.

\section{For clinicians}

Adenosine is the safer option in clinical situations for which verapamil is clearly contraindicated, as when people who have hypotension and poor left ventricular function are already taking beta-blockers, when individuals have other tachyarrhythmias such as broad complex tachycardia, or when a rapid effect is essential (as in very unstable or highly symptomatic patients). Verapamil is suggested for patients with asthma, as well as for stable patients in whom an extra 5 minutes is not likely to result in a worse clinical outcome, patients treated with adenosine in the past who experienced uncomfortable side effects that they would rather avoid if possible, patients who relapsed to SVT shortly after receiving adenosine because of frequent ectopics, and patients with frequent atrial or ventricular ectopics that could trigger a new episode of arrhythmia.

\section{For funders and policy makers}

Although current guidelines recommend adenosine as the first treatment choice, we could not confirm its superiority versus CCAs (Blomstrom-Lundqvist 2003; Page 2016; Resuscitation Council (UK) 2015). Therefore, future updated versions of these guidelines might consider the evidence presented in this review.

\section{Implications for research}

The main gap in our current knowledge involves which treatment patients prefer. Studies comparing patient experiences and adverse events are needed to fully answer whether one treatment is preferable in the management of SVT.

\section{ACKNOWLEDGEMENTS}

The authors of this updated review thank the authors of the original version of this review, A Holdgate and A Foo.

The authors of this review update would like to thank Charlene Bridge, Nicole Martin and all the peer reviewers, editors and copyeditors from the Cochrane Heart Group for providing precious help. 
R E F E R E N C E S

\section{References to studies included in this review}

Cabrera-Sole 1989 \{published data only\}

Cabrera-Sole R, Abeytua M, Lopez Bescos L, Rubio R. Paroxysmal supraventricular tachycardia: efficacy of adenosine versus verapamil. Revista Espanola de Cardiologia 1989;42(Suppl 2):19. [MEDLINE: 15]

\section{Cheng 2003 \{published data only\}}

Cheng KA. A randomized, multicenter trial to compare the safety and efficacy of adenosine versus verapamil for termination of paroxysmal supraventricular tachycardia. Chinese Journal of Internal Medicine 2003;42:773-6. [MEDLINE: 17]

\section{Ferreira 1996 \{published data only\}}

Ferreira JFM, Pamplona D, Cesar LAM, Leite PF, Sosa EA, Da Luz PL, et al. Adenosin-three phosphate compared with verapamil to treat paroxysmal supraventricular tachycardia. Arquivos Brasileros de Cardiologia 1996;66:55-7. [MEDLINE: 7]

Gil Madre 1995 \{published data only\}

Gil Madre J, Lazaro Rodriguez S, Sentenac Marchan G, Sepulveda Berrocal MA, Alises Moraleda JM, Cortes Bermejo S, et al. Adenosin triphosphate and the treatment of paroxysmal supraventricular tachycardia: a comparison with verapamil. Revista Espanola de Cardiologia 1995;48:55-8. [MEDLINE: 10]

\section{Greco 1982 \{published data only\}}

Greco R, Musto B, Arienzo V, et al. Treatment of paroxysmal supraventricular tachycardia in infancy with digitalis, adenosine-5'-triphosphate and verapamil: a comparative study. Circulation 1982;66:504-8. [MEDLINE: 16]

\section{Lim 2009 \{published data only\}}

Lim SH, Anantharaman V, Teo WS, Chan YH. Slow infusion of calcium channel blockers compared with intravenous adenosine in the emergency treatment of supraventricular tachycardia. Resuscitation 2009;80(5):523-8.

\section{Vranic 2006 \{published data only\}}

Vranic II, Matic M, Perunicic J, Simic T, Soskic L, Milic N. Adenosine cardioprotection study in clinical setting of paroxysmal supraventricular tachycardia. Prostaglandins, Leukotrienes, and Essential Fatty Acids 2006;74(6):365-71.

\section{References to studies excluded from this review}

\section{Athar 2013 \{published data only\}}

Athar M, Majid A, Hussain A, Haider I, Shahid N, Ahmed I, et al. Comparison of efficacy of intravenous adenosine and verapamil in acute paroxysmal supraventricular tachycardia in adults. Journal of Sheikh Zayed Medical College (JSZMC) 2013;4(3):492-6.

\section{Ballo 2004 \{published data only\}}

Ballo P, Bernabo D, Faraguti SA. Heart rate is a predictor of success in the treatment of adults with symptomatic paroxysmal supraventricular tachycardia. European Heart Journal 2004;25:1310-7. [MEDLINE: 2]
Belhassen 1984 \{published data only\}

Belhassen B, Pelleg A. Acute management of supraventricular tachycardia: verapamil, adenosine triphosphate or adenosine? American Journal of Cardiology 1984;54:225-7. [MEDLINE: 20]

Conti 1995 \{published data only\}

Conti Gimenez LA, Gil Madre J. Adenosine triphosphate and the treatment of paroxysmal supraventricular tachycardia: a comparison with verapamil. Revista Espanola de Cardiologia 1995;48:499-500. [MEDLINE: 8]

\section{DiMarco 1990 \{published data only\}}

DiMarco JP, Miles W, Akhtar M, Milstein S, Sharma AD, Platia E, et al. Adenosine for paroxysmal supraventricular tachycardia: dose ranging and comparison with verapamil. Assessment in placebo-controlled, multicenter trials.. Annals of Internal Medicine 1990;113:104-10. [MEDLINE: 13]

\section{Garratt 1989 \{published data only\}}

Garratt C, Linker N, Griffith M, Ward D, Camm AJ. Comparison of adenosine and verapamil for termination of paroxysmal junctional tachycardia. American Journal of Cardiology 1989;64:1310-6. [MEDLINE: 14]

\section{Gill 2014 \{published data only\}}

Gill BU, Bukhari SN, Rashid MA, Saleemi MS, Zaffar MZ. Comparing the efficacy of intravenous adenosine and verapamil in termination of acute paroxysmal supra ventricular tachycardia. Journal of Ayub Medical College Abbottabad 2014;26(1):29-31.

\section{Hood 1992 \{published data only\}}

Hood MA, Smith WM. Adenosine versus verapamil in the treatment of supraventricular tachycardia: a randomized double-crossover trial. American Heart Journa 1992;123:1543-9. [MEDLINE: 11]

\section{Kulakowski 1998 \{published data only\}}

Kulakowski P, Karpinski G, Karczmarewicz S, Czepiel A, Makowska E, Soszynska M. Efficacy and safety of adenosine in termination of paroxysmal supraventricular tachycardia: comparison with verapamil. Kardiologia Polska 1998;49:295-303. [MEDLINE: 3]

\section{Rankin 1991 \{published data only\}}

Rankin AC, McGovern BA. Adenosine or verapamil for the acute treatment of supraventricular tachycardia?. Annals of Internal Medicine 1991;114:513-5. [MEDLINE: 18]

Riaz 2012 \{published data only\}

Riaz R, Mishra J, Hussain S, Sinha LM. Adenosine versus verapamil for the treatment of supra-ventricular tachycardia: randomized comparative trial. Pakistan Journal of Medical and Health Sciences 2012;6(3):541-3.

Sellers 1987 \{published data only\}

Sellers TD, Kirchhoffer JB, Modesto TA. Adenosine: a clinical experience and comparison with verapamil for the termination 
of supraventricular tachycardias. Progress in Clinical and Biological Research 1987;230:283-99. [MEDLINE: 19]

\section{Sethi 1994 \{published data only\}}

Sethi KK, Singh B, Kalra GS, Arora R, Khalilullah M. Comparative clinical and electrophysiologic effects of adenosine and verapamil on termination of paroxysmal supraventricular tachycardia. Indian Heart Journal 1994;46:141-4. [MEDLINE: 9]

\section{Shaker 2015 \{published data only\}}

Shaker H, Jahanian F, Fathi M, Zare M. Oral verapamil in paroxysmal supraventricular tachycardia recurrence control: a randomized clinical trial. Therapeutic Advances in Cardiovascular Disease 2015;9(1):4-9. [PUBMED: 25297337]

\section{Trappe 1997 \{published data only\}}

Trappe H-J. Acute management of supraventricular tachycardia: adenosine or ajmaline?. Intensivmedizin und Notfallmedizin 1997;34:452-61. [MEDLINE: 4]

\section{Turkoglu 1996 \{published data only\}}

Turkoglu C, Firatli I, Turkoglu C, Ozturk M. Effect of adenosine in termination of induced supraventricular tachycardias and comparison with verapamil. Turk Kardiyoloji Dernegi Arsivi 1996;24:452-61. [MEDLINE: 5]

\section{Turkoglu 2009 \{published data only\}}

Turkoglu C, Ozturk M, Aliyev F, Firatli I, Incesoy N. Electrophysiologic characteristics of wide QRS complexes during pharmacologic termination of sustained supraventricular tachycardias with verapamil and adenosine: observations from electrophysiologic study. Annals of Noninvasive Electrocardiology 2009;14(4):375-80.

\section{Additional references}

\section{ACLS 2015}

de Caen AR, Berg MD, Chameides L, Gooden CK, Hickey RW, Scott HF, et al. Part 12: Pediatric advanced life support. Circulation 2015;132(18 Suppl 2):S526.

\section{Appelboam 2015}

Appelboam A, Reuben A, Mann C, Gagg J, Ewings P, Barton A, et al. Postural modification to the standard Valsalva manoeuvre for emergency treatment of supraventricular tachycardias (REVERT): a randomised controlled trial. Lancet (London, England) 2015;386(10005):1747-53. [PUBMED: 26314489]

\section{Blomstrom-Lundqvist 2003}

Blomstrom-Lundqvist C, Scheinman MM, Aliot EM, Alpert JS, Calkins H, Camm AJ, et al. ACC/AHA/ESC Guidelines for the Management of Patients With Supraventricular Arrhythmias-Executive Summary. A report of the American College of Cardiology/American Heart Association Task Force on Practice Guidelines and the European Society of Cardiology Committee for Practice Guidelines (writing committee to develop guidelines for the management of patients with supraventricular arrhythmias) developed in collaboration with NASPE-Heart Rhythm Society. Journal of the American College of Cardiology 2003;42(8):1493-531. [PUBMED: 14563598]

\section{Bolton 2000}

Bolton E. Disturbances of cardiac rhythm and conduction. In: Tintinalli JE, Kelen GD, Stapczynski JS editor(s). Emergency Medicine - a Comprehensive Study Guide. 5th Edition. New York: McGraw-Hill, 2000:169-78.

\section{Carlisle 2015}

Carlisle JB, Dexter F, Pandit JJ, Shafer SL, Yentis SM. Calculating the probability of random sampling for continuous variables in submitted or published randomised controlled trials. Anaesthesia 2015;70(7):848-58. [PUBMED: 26032950]

\section{Carlisle 2017}

Carlisle JB. Data fabrication and other reasons for non-random sampling in 5087 randomised, controlled trials in anaesthetic and general medical journals. Anaesthesia 2017;n/a:n/a.

\section{Delacrétaz 2006}

Delacrétaz E. Supraventricular tachycardia. New England Journal of Medicine 2006;354:1039-51.

\section{Delaney 2011}

Delaney B, Loy J, Kelly AM. The relative efficacy of adenosine versus verapamil for the treatment of stable paroxysmal supraventricular tachycardia in adults: a meta-analysis. European Journal of Emergency Medicine 2011;18(3):148-52. [PUBMED: 20926952]

\section{Dougherty 1992}

Dougherty AH, Jackman WM, Naccarelli GV, Friday KJ, Dias VC. Acute conversion of paroxysmal supraventricular tachycardia. IV Diltiazem Study Group. American Journal of Cardiology 1992;70:587-92.

\section{Faulds 1991}

Faulds D, Crisp P, Buckley MM. Adenosine. An evaluation of its use in diagnostic procedures, and in the treatment of paroxysmal supraventricular tachycardia. Drugs 1991;41:596-624.

\section{Ferguson 2003}

Ferguson JD, DiMarco JP. Contemporary management of paroxysmal supraventricular tachycardia. Circulation 2003;107:1096-9.

\section{GRADEproGDT 2015 [Computer program]}

Hamilton (ON): McMaster University (developed by Evidence Prime). GRADEproGDT. Version accessed 10 May 2017. Hamilton (ON): McMaster University (developed by Evidence Prime), 2015.

\section{Gupta 1999}

Gupta A, Naik A, Vora A, Lokhandwala Y. Comparison of the efficacy of diltiazem and esmolol in terminating supraventricular tachycardia. Journal of the Association of Physicians of India 1999;47:969-72.

\section{Higgins 2011}

Higgins JP, Green S, editors. Cochrane Handbook for Systematic Reviews of Interventions Version 5.1.0 (updated March 2011). The Cochrane Collaboration, 2011. Available from www.cochrane-handbook.org. 


\section{Jayam 2004}

Jayam VKS, Calkins H. Supraventricular tachycardia, AV nodal reentry and Wolff-Parkinson-White syndrome. Hurst's The Heart. 11th Edition. New York: McGraw Hill, 2004:855-73.

\section{Jordaens 1991}

Jordaens L, Gorgels A, Stroobandt R, Temmerman J. Efficacy and safety of intravenous sotalol for termination of supraventricular tachycardia. The Sotalol Versus Placebo Multicenter Study Group. American Journal of Cardiology 1991;68:35-40.

\section{Joshi 1995}

Joshi PP, Deshmukh PK, Salkar RG. Efficacy of intravenous magnesium sulphate in supraventricular tachyarrhythmias. Journal of the Association of Physicians of India 1995;43:529-31.

\section{Katzung 1995}

Hondeghem LM, Roden DM. Agents used in cardiac arrhythmias. In: Katzung BG editor(s). Basic and Clinical Pharmacology. 6th Edition. Connecticut: Prentice-Hall International, 1995.

\section{Lefebvre 2011}

Lefebvre C, Manheimer E, Glanville J. Chapter 6: Searching for studies. Higgins JPT, Green S, editors. Cochrane Handbook for Systematic Reviews of Interventions Version 5.1.0 (updated March 2011). The Cochrane Collaboration, 2011.

\section{Mangrum 2002}

Mangrum JM, DiMarco JP. Acute and chronic pharmacologic management of supraventricular arrhythmias in cardiovascular therapeutics. In: Antman E editor(s). Cardiovascular Therapeutics: A Companion to Braunwald's Heart Disease. 2nd Edition. Philadelphia, PA: WB Saunders, 2002:423-44.

\section{Medi 2009}

Medi C, Kalman JM, Freedman SB. Supraventricular tachycardia. The Medical Journal of Australia 2009;190(5):255-60. [PUBMED: 19296791]

\section{Orejarena 1998}

Orejarena LA, Vidaillet H Jr, DeStefano F, et al. Paroxysmal supraventricular tachycardia in the general population. Journal of the American College of Cardiology 1998;31:150-7.

\section{Page 2016}

Page RL, Joglar JA, Caldwell MA, Calkins H, Conti JB, Deal BJ, et al. 2015 ACC/AHA/HRS Guideline for the Management of Adult Patients With Supraventricular Tachycardia: A Report of the American College of Cardiology/American Heart Association Task Force on Clinical Practice Guidelines and the Heart Rhythm Society. Journal of the American College of Cardiology 2016;67(13):e27-e115. [DOI: 10.1016/j.jacc.2015.08.856]

\section{Resuscitation Council (UK) 2015}

Pitcher D, Nolan J. Peri-arrest arrhythmias. https:// www.resus.org.uk/resuscitation-guidelines/peri-arrestarrhythmias/ 2015:Version accessed 10 July 2016.

\section{RevMan 5.3 [Computer program]}

The Nordic Cochrane Centre, The Cochrane Collaboration. Review Manager 5 (RevMan 5). Version 5.3. Copenhagen: The Nordic Cochrane Centre, The Cochrane Collaboration, 2014.

\section{Schünemann 2011}

Schünemann H, Oxman A, Gunn V, Higgins J, Deeks J, Glasziou P, et al. Chapter 11: Presenting results and "Summary of findings" tables. In: Higgins JP, Green S editor(s). Cochrane Handbook for Systematic Reviews of Interventions Version 5.1.0 (updated March 2011). The Cochrane Collaboration, 2011.

\section{Smith 2015}

Smith GD, Fry MM, Taylor D, Morgans A, Cantwell K. Effectiveness of the Valsalva manoeuvre for reversion of supraventricular tachycardia. Cochrane Database of Systematic Reviews 2015, Issue 2. [DOI: 10.1002/14651858.CD009502.pub3]

\section{Soar 2015}

Soar J, Nolan JP, Bottiger BW, Perkins GD, Lott C, Carli P, et al. European Resuscitation Council Guidelines for Resuscitation 2015: Section 3. Adult advanced life support. Resuscitation 2015;95:100-47. [PUBMED: 26477701]

\section{Sterne 2011}

Sterne JAC, Egger M, Moher D. Chapter 10: Addressing reporting biases. In: Higgins JP, Green S editor(s). Cochrane Handbook for Systematic Reviews of Interventions. The Cochrane Collaboration, 2011.

\section{Wen 1998}

Wen ZC, Chen SA, Tai CT, Chiang CE, Chiou CW, Chang MS. Electrophysiological mechanisms and determinants of vagal manoeuvres for termination of paroxysmal supraventricular tachycardia. Circulation 1998;98:2716-23.

\section{References to other published versions of this review}

\section{Holdgate 2005}

Holdgate A, Foo A. Adenosine versus intravenous calcium channel antagonists for the treatment of supraventricular tachycardia in adults. Cochrane Database of Systematic Reviews 2005, Issue 1. [DOI: 10.1002/14651858.CD005154]

\section{Holdgate 2006}

Holdgate A, Foo A. Adenosine versus intravenous calcium channel antagonists for the treatment of supraventricular tachycardia in adults. Cochrane Database of Systematic Reviews 2006, Issue 4. [DOI: 10.1002/14651858.CD005154.pub2; PUBMED: 17054240$]$

\section{CHARACTERISTICS OF STUDIES}

Characteristics of included studies [ordered by study ID] 
Cabrera-Sole 1989

\begin{tabular}{ll}
\hline Methods & RCT \\
\hline Participants & Age not stated, presumed adult \\
Gp 1: 44 participants \\
Gp 2: 43 participants \\
Inclusion criteria: SVT \\
Exclusion criteria: not stated \\
\hline Gp 1: ATP 20 mg bolus \\
Gp 2: verapamil 10 mg bolus \\
\hline Outcomes & Reversion rate \\
Minor A/E
\end{tabular}

\section{Risk of bias}

\begin{tabular}{lll}
\hline Bias & Authors' judgement & Support for judgement \\
\hline $\begin{array}{l}\text { Random sequence genera- } \\
\text { tion (selection bias) }\end{array}$ & Unclear risk & Randomisation performed, but method not specified \\
\hline $\begin{array}{l}\text { Allocation concealment } \\
\text { (selection bias) }\end{array}$ & Unclear risk & $\begin{array}{l}\text { Information insufficient to determine whether allocation concealment was ad- } \\
\text { equate }\end{array}$
\end{tabular}

Blinding of participants High risk Treatment was not blinded.

and personnel (perfor-

mance bias)

All outcomes

Blinding of outcome as- High risk No attempt at blinding intervention was made.

sessment (detection bias)

All outcomes

$\begin{array}{ll}\begin{array}{l}\text { Incomplete outcome data } \\ \text { (attrition bias) }\end{array} & \text { Low risk } \\ \text { Nolosses to follow-up, withdrawals, dropouts, or protocol deviations were re- } \\ \text { ported. }\end{array}$

All outcomes ported.

\begin{tabular}{|c|c|c|}
\hline $\begin{array}{l}\text { Selective reporting (re- } \\
\text { porting bias) }\end{array}$ & Unclear risk & $\begin{array}{l}\text { protocol was available for comparison of intended study outcome } \\
\text { ed outcomes. }\end{array}$ \\
\hline
\end{tabular}

Other bias Unclear risk No mention of funding and no mention of possible conflicts of interest

Cheng 2003

\begin{tabular}{ll}
\hline Methods & RCT \\
\hline Participants & Adults 18 to 75 years \\
Gp 1: 60 participants (29 M) \\
Gp 2: 62 participants (25 M) \\
Inclusion criteria: paroxysmal SVT \\
Exclusion criteria: heart block; asthma; emphysema; tea/coffee; taking beta-blocker, Ca antagonist, or \\
other antihypertensive or antiarrhythmics; pregnancy or breastfeeding
\end{tabular}


Cheng 2003 (Continued)

Interventions
Gp 1: Adenosine $3 \mathrm{mg}$, then $6 \mathrm{mg}$, then $9 \mathrm{mg}$ every 1 to 2 minutes if no response to previous dose. Mean dose $9.63 \mathrm{mg}$

Gp 2: Verapamil $5 \mathrm{mg}$ over 5 minutes, repeated if no reversion by 15 minutes. Mean dose $7.15 \mathrm{mg}$

\begin{tabular}{ll}
\hline Outcomes & $\begin{array}{l}\text { Reversion rate } \\
\text { Time to reversion } \\
\text { Minor A/E }\end{array}$ \\
\hline Notes & Country: China
\end{tabular}

\section{Risk of bias}

\begin{tabular}{|c|c|c|}
\hline Bias & Authors' judgement & Support for judgement \\
\hline $\begin{array}{l}\text { Random sequence genera- } \\
\text { tion (selection bias) }\end{array}$ & Unclear risk & Randomisation mentioned, but method not specified \\
\hline $\begin{array}{l}\text { Allocation concealment } \\
\text { (selection bias) }\end{array}$ & Unclear risk & $\begin{array}{l}\text { Information insufficient to determine whether allocation concealment was ad- } \\
\text { equate }\end{array}$ \\
\hline $\begin{array}{l}\text { Blinding of participants } \\
\text { and personnel (perfor- } \\
\text { mance bias) } \\
\text { All outcomes }\end{array}$ & High risk & Treatment was not blinded. \\
\hline $\begin{array}{l}\text { Blinding of outcome as- } \\
\text { sessment (detection bias) } \\
\text { All outcomes }\end{array}$ & High risk & No attempt at blinding intervention was made. \\
\hline $\begin{array}{l}\text { Incomplete outcome data } \\
\text { (attrition bias) } \\
\text { All outcomes }\end{array}$ & Low risk & $\begin{array}{l}\text { No losses to follow-up, withdrawals, dropouts, or protocol deviations were re- } \\
\text { ported. }\end{array}$ \\
\hline $\begin{array}{l}\text { Selective reporting (re- } \\
\text { porting bias) }\end{array}$ & Unclear risk & $\begin{array}{l}\text { No study protocol was available for comparison of intended study outcomes } \\
\text { vs reported outcomes. }\end{array}$ \\
\hline Other bias & Unclear risk & No mention of funding and no mention of possible conflicts of interest \\
\hline
\end{tabular}

\section{Ferreira 1996}

\begin{tabular}{ll}
\hline Methods & RCT with cross-over design \\
\hline Participants & Adults \\
& Gp 1: $25(8 \mathrm{M})$ \\
& Gp 2: $25(9 \mathrm{M})$ \\
& Inclusion criteria: paroxysmal SVT presenting to ED \\
& Exclusion criteria: SBP < 90, low output state, CCF, UAP, recent MI, taking dipyridamole or methylxan- \\
& thine \\
\hline Interventions & Gp 1: ATP $10 \mathrm{mg}$, then $20 \mathrm{mg}$ bolus if needed. Mean dose $10.8 \mathrm{mg}$ \\
& Gp 2: Verapamil infused at $5 \mathrm{mg} / \mathrm{min}$ up to $15 \mathrm{mg}$ if needed. Mean dose $9.38 \mathrm{mg}$ \\
\hline Outcomes & Reversion rate \\
& Time to reversion \\
& Recurrence rate \\
& Minor A/E
\end{tabular}


Ferreira 1996 (Continued)

Major A/E

Notes Country: Brazil

\section{Risk of bias}

\begin{tabular}{|c|c|c|}
\hline Bias & Authors' judgement & Support for judgement \\
\hline $\begin{array}{l}\text { Random sequence genera- } \\
\text { tion (selection bias) }\end{array}$ & Unclear risk & Randomisation mentioned, but method not specified \\
\hline $\begin{array}{l}\text { Allocation concealment } \\
\text { (selection bias) }\end{array}$ & Unclear risk & $\begin{array}{l}\text { Information insufficient to determine whether allocation concealment was ad- } \\
\text { equate }\end{array}$ \\
\hline $\begin{array}{l}\text { Blinding of participants } \\
\text { and personnel (perfor- } \\
\text { mance bias) } \\
\text { All outcomes }\end{array}$ & High risk & Treatment was not blinded. \\
\hline $\begin{array}{l}\text { Blinding of outcome as- } \\
\text { sessment (detection bias) } \\
\text { All outcomes }\end{array}$ & High risk & No attempt at blinding intervention was made. \\
\hline $\begin{array}{l}\text { Incomplete outcome data } \\
\text { (attrition bias) } \\
\text { All outcomes }\end{array}$ & Low risk & $\begin{array}{l}\text { No losses to follow-up, withdrawals, dropouts, or protocol deviations were re- } \\
\text { ported. }\end{array}$ \\
\hline $\begin{array}{l}\text { Selective reporting (re- } \\
\text { porting bias) }\end{array}$ & Unclear risk & $\begin{array}{l}\text { No study protocol was available for comparison of intended study outcomes } \\
\text { vs reported outcomes. }\end{array}$ \\
\hline Other bias & Unclear risk & No mention of funding and no mention of possible conflicts of interest \\
\hline
\end{tabular}

\section{Gil Madre 1995}

\begin{tabular}{ll}
\hline Methods & RCT with cross-over design \\
\hline Participants & Adults $(25 \mathrm{M}, 25 \mathrm{~F})$ \\
& Gp 1: 26 participants \\
Gp 2: 24 participants \\
Inclusion criteria: SVT without haemodynamic instability, unresponsive to vagal manoeuvres \\
Exclusion criteria: SBP < 80, current treatment with beta-blockers or Ca antagonists, known ventricular \\
dysfunction, asthma, recent treatment with dipyridamole \\
\hline Interventions & Gp 1: ATP 5 mg, then 10 mg, then 20 mg every 1 minute if previous dose not effective \\
& Gp 2: 5 mg over 3 minutes, repeated after 10 minutes if no response to first dose \\
\hline Outcomes & Reversion rate \\
Relapse rate & Minor A/E \\
\hline Notes & Country: Spain \\
\hline
\end{tabular}

\section{Risk of bias}

Bias Authors' judgement Support for judgement


Gil Madre 1995 (Continued)

\begin{tabular}{lll}
$\begin{array}{l}\text { Random sequence genera- } \\
\text { tion (selection bias) }\end{array}$ & Unclear risk & Randomisation mentioned, but method not specified \\
\hline $\begin{array}{l}\text { Allocation concealment } \\
\text { (selection bias) }\end{array}$ & Unclear risk & $\begin{array}{l}\text { Information insufficient to determine whether allocation concealment was ad- } \\
\text { equate }\end{array}$ \\
\hline $\begin{array}{l}\text { Blinding of participants } \\
\text { and personnel (perfor- } \\
\text { mance bias) }\end{array}$ & High risk & Treatment was not blinded. \\
All outcomes & &
\end{tabular}

\begin{tabular}{lll}
\hline $\begin{array}{l}\text { Blinding of outcome as- } \\
\text { sessment (detection bias) } \\
\text { All outcomes }\end{array}$ & High risk & No attempt at blinding intervention was made. \\
\hline $\begin{array}{l}\text { Incomplete outcome data } \\
\text { (attrition bias) }\end{array}$ & Low risk & $\begin{array}{l}\text { No losses to follow-up, withdrawals, dropouts, or protocol deviations were re- } \\
\text { All outcomes }\end{array}$
\end{tabular}

All outcomes

\begin{tabular}{|c|c|c|}
\hline $\begin{array}{l}\text { Selective reporting (re- } \\
\text { porting bias) }\end{array}$ & Unclear risk & $\begin{array}{l}\text { No study protocol was available for comparison of intended study outcomes } \\
\text { vs reported outcomes. }\end{array}$ \\
\hline
\end{tabular}

\begin{tabular}{ll}
\hline Other bias $\quad$ Unclear risk $\quad$ No mention of funding and no mention of possible conflicts of interest \\
\hline
\end{tabular}

Greco 1982

\begin{tabular}{|c|c|c|}
\hline Methods & \multicolumn{2}{|c|}{ RCT with cross-over design } \\
\hline Participants & \multicolumn{2}{|c|}{$\begin{array}{l}\text { Children < } 13 \text { years } \\
\text { Gp 1: } 20 \text { participants } \\
\text { Gp 2: } 23 \text { participants } \\
\text { Inclusion criteria: presentation with paroxysmal SVT } \\
\text { Exclusion criteria: shock or response to vagal manoeuvre }\end{array}$} \\
\hline Interventions & \multicolumn{2}{|c|}{$\begin{array}{l}\text { Gp 1: ATP titrated to effect, mean dose } 7.46 \mathrm{mg} \\
\text { Gp 2: verapamil titrated to effect, mean dose } 2.09 \mathrm{mg}\end{array}$} \\
\hline Outcomes & \multicolumn{2}{|l|}{$\begin{array}{l}\text { Reversion rate } \\
\text { Minor } \mathrm{A} / \mathrm{E}\end{array}$} \\
\hline Notes & \multicolumn{2}{|c|}{$\begin{array}{l}\text { Two-part study; only participants in second part included, as no randomisation in first part } \\
\text { Country: Italy }\end{array}$} \\
\hline \multicolumn{3}{|l|}{ Risk of bias } \\
\hline Bias & Authors' judgement & Support for judgement \\
\hline $\begin{array}{l}\text { Random sequence genera- } \\
\text { tion (selection bias) }\end{array}$ & Low risk & Random numbers table \\
\hline $\begin{array}{l}\text { Allocation concealment } \\
\text { (selection bias) }\end{array}$ & Unclear risk & $\begin{array}{l}\text { Information insufficient to determine whether allocation concealment was ad- } \\
\text { equate }\end{array}$ \\
\hline
\end{tabular}


Greco 1982 (Continued)

Blinding of participants High risk $\quad$ Treatment was not blinded.
and personnel (perfor-

mance bias)

All outcomes

$\begin{array}{ll}\text { Blinding of outcome as- } & \text { High risk } \quad \text { No attempt at blinding intervention was made. } \\ \text { sessment (detection bias) }\end{array}$

All outcomes

Incomplete outcome data Low risk (attrition bias)

All outcomes
No losses to follow-up, withdrawals, dropouts, or protocol deviations were reported.

\begin{tabular}{|c|c|c|}
\hline $\begin{array}{l}\text { Selective reporting (re- } \\
\text { porting bias) }\end{array}$ & Unclear risk & $\begin{array}{l}\text { No study protocol was available for comparison of intended study outcomes } \\
\text { vs reported outcomes. }\end{array}$ \\
\hline
\end{tabular}

Other bias Unclear risk No mention of funding and no mention of possible conflicts of interest

Lim 2009

\begin{tabular}{|c|c|}
\hline Methods & RCT with cross-over design \\
\hline \multirow[t]{7}{*}{ Participants } & 233 participants with spontaneous regular narrow complex tachycardia \\
\hline & and failed Valsalva manoeuvres \\
\hline & Gp 1: 104 participants on adenosine, mean age $50.6 \pm 17.0,42 \%$ males \\
\hline & $\begin{array}{l}\text { Gp 1: } 102 \text { participants on verapamil ( } 57 \text { people) and diltiazem (59 people). Mean age } 48.9 \pm 18.3,40 \% \\
\text { males }\end{array}$ \\
\hline & 27 excluded from analysis after enrolment, as they had an arrhythmia other than SVT \\
\hline & $\begin{array}{l}\text { Inclusion criteria: at least } 10 \text { years of age with regular narrow complex tachycardia and an electrocar- } \\
\text { diographic (ECG) diagnosis of SVT, not converted by vagal manoeuvres (Valsalva manoeuvre or carotid } \\
\text { sinus massage or both) }\end{array}$ \\
\hline & $\begin{array}{l}\text { Exclusion criteria: signs of impaired cerebral perfusion (e.g. altered mental state) or acute pulmonary } \\
\text { oedema }\end{array}$ \\
\hline \multirow[t]{5}{*}{ Interventions } & Gp 1: adenosine, initially a 6-mg bolus, then a $12-\mathrm{mg}$ bolus after 2 minutes, if needed \\
\hline & Gp 2: verapamil and diltiazem \\
\hline & Verapamil: slow intravenous infusion at a rate of $1 \mathrm{mg}$ per minute, up to a maximum dose of $20 \mathrm{mg}$ \\
\hline & Diltiazem: slow intravenous infusion at a rate of $2.5 \mathrm{mg}$ per minute, up to a maximum dose of $50 \mathrm{mg}$ \\
\hline & $\begin{array}{l}\text { Refractory cases were crossed-over if initial intervention was not successful after repeated admissions. } \\
\text { These cases were counted as failures of the intervention and were not included in the final analysis. }\end{array}$ \\
\hline \multirow[t]{3}{*}{ Outcomes } & Reversion rate \\
\hline & Relapse rate: recurrences during 2-hour observation period \\
\hline & Major adverse event: hypotension \\
\hline \multirow[t]{2}{*}{ Notes } & ED of the Singapore General Hospital \\
\hline & Country: Singapore \\
\hline
\end{tabular}


Lim 2009 (Continued)

Risk of bias

\begin{tabular}{|c|c|c|}
\hline Bias & Authors' judgement & Support for judgement \\
\hline $\begin{array}{l}\text { Random sequence genera- } \\
\text { tion (selection bias) }\end{array}$ & Low risk & $\begin{array}{l}\text { Randomisation was performed by a nurse who drew a serialised sealed enve- } \\
\text { lope. }\end{array}$ \\
\hline $\begin{array}{l}\text { Allocation concealment } \\
\text { (selection bias) }\end{array}$ & Low risk & Participants were randomised with the use of sealed envelopes. \\
\hline $\begin{array}{l}\text { Blinding of participants } \\
\text { and personnel (perfor- } \\
\text { mance bias) } \\
\text { All outcomes }\end{array}$ & High risk & $\begin{array}{l}\text { Interventions were given by different methods, and no attempt at blinding in- } \\
\text { tervention was made. }\end{array}$ \\
\hline $\begin{array}{l}\text { Blinding of outcome as- } \\
\text { sessment (detection bias) } \\
\text { All outcomes }\end{array}$ & High risk & Not mentioned \\
\hline $\begin{array}{l}\text { Incomplete outcome data } \\
\text { (attrition bias) } \\
\text { All outcomes }\end{array}$ & Low risk & $\begin{array}{l}\text { Twenty-seven participants were excluded from analysis, as they were found } \\
\text { not to have SVT after enrolment. Therefore, } 15 \% \text { of participants were not } \\
\text { analysed in the groups to which they were randomised. } \\
\text { However, as participants were randomised, excluded patients were closely } \\
\text { distributed across intervention groups and had similar reasons for exclusion. }\end{array}$ \\
\hline $\begin{array}{l}\text { Selective reporting (re- } \\
\text { porting bias) }\end{array}$ & Low risk & $\begin{array}{l}\text { The main outcomes reported are the same as those planned at a prospective } \\
\text { trial registration. }\end{array}$ \\
\hline Other bias & Low risk & $\begin{array}{l}\text { Study authors declared no conflicts of interest. The Department of Clinical Re- } \\
\text { search, Singapore General Hospital, funded adenosine and diltiazem. }\end{array}$ \\
\hline
\end{tabular}

Vranic 2006

\begin{tabular}{ll}
\hline Methods & RCT \\
\hline Participants & Adults with spontaneous SVT or WPW \\
& 64 consecutive patients with diagnosis of acute SVT or WPW syndrome \\
& Males $48.4 \%$ \\
& Mean age of men was $47 \pm 12$ years, and women $48 \pm 12$ years \\
& Inclusion criteria: older than 18 years of age with abrupt onset of SVT lasting 20 to 30 minutes \\
& Exclusion criteria: presence of atrial flutter, asthma or chronic obstructive pulmonary disease, long- \\
term use of dipyridamole or theophylline derivatives, pregnant or breastfeeding women, any heart & disease apart from coronary artery disease (different forms of stenotic lesions of major arteries or \\
veins), heart failure or pulmonary heart disease, history of bleeding diathesis, stroke, hypertension over \\
200/110 mmHg, severe diseases of liver or renal function (anamnestic data), confirmed malignancies, \\
severe genetic diseases, severe anaemia, alcohol or narcotic addiction, psychiatric disorders, AV block \\
of second \\
or third degree, sick sinus syndrome
\end{tabular}

Interventions

$\mathrm{Gp}$ 1: adenosine IV bolus of $6 \mathrm{mg}$, then $12 \mathrm{mg}$ if needed 
Vranic 2006 (Continued)

Gp 2: verapamil or IV $5 \mathrm{mg}$ up to maximum dose of $10 \mathrm{mg}$ if needed

\begin{tabular}{|c|c|c|}
\hline \multirow[t]{4}{*}{ Outcomes } & \multicolumn{2}{|c|}{ Cardioversion into sinus rhythm } \\
\hline & \multicolumn{2}{|c|}{ Duration to sinus rhythm conversion } \\
\hline & \multicolumn{2}{|l|}{ Relapse } \\
\hline & \multicolumn{2}{|l|}{ Biomarkers outcomes } \\
\hline \multirow[t]{2}{*}{ Notes } & \multicolumn{2}{|c|}{ Intensive care unit and emergency centre at Clinical Center of Serbia } \\
\hline & \multicolumn{2}{|l|}{ Country: Serbia } \\
\hline \multicolumn{3}{|l|}{ Risk of bias } \\
\hline Bias & Authors' judgement & Support for judgement \\
\hline $\begin{array}{l}\text { Random sequence genera- } \\
\text { tion (selection bias) }\end{array}$ & Unclear risk & Sequence generation and randomisation method not mentioned \\
\hline $\begin{array}{l}\text { Allocation concealment } \\
\text { (selection bias) }\end{array}$ & Unclear risk & Not mentioned \\
\hline $\begin{array}{l}\text { Blinding of participants } \\
\text { and personnel (perfor- } \\
\text { mance bias) } \\
\text { All outcomes }\end{array}$ & High risk & $\begin{array}{l}\text { Interventions given by different methods and no attempt at blinding interven- } \\
\text { tion made }\end{array}$ \\
\hline $\begin{array}{l}\text { Blinding of outcome as- } \\
\text { sessment (detection bias) } \\
\text { All outcomes }\end{array}$ & High risk & Not mentioned \\
\hline $\begin{array}{l}\text { Incomplete outcome data } \\
\text { (attrition bias) } \\
\text { All outcomes }\end{array}$ & Low risk & $\begin{array}{l}\text { Interventions were applied and outcomes were assessed within the depart- } \\
\text { ment. No losses to follow-up, withdrawals, or dropouts were reported. }\end{array}$ \\
\hline $\begin{array}{l}\text { Selective reporting (re- } \\
\text { porting bias) }\end{array}$ & Unclear risk & $\begin{array}{l}\text { No study protocol was available for comparison of intended study outcomes } \\
\text { vs reported outcomes. }\end{array}$ \\
\hline Other bias & Unclear risk & No mention of funding and no mention of possible conflicts of interest \\
\hline
\end{tabular}

A/E: adverse events.

ATP: adenosine triphosphate.

AV: atrioventricular.

CCF: congestive cardiac failure.

ECG: electrocardiogram.

ED: emergency department.

MI: myocardial infarction.

$\mathrm{RCT}$ : randomised controlled trial.

SBP: systolic blood pressure.

SVT: supraventricular tachycardia.

UAP: unstable angina pectoris.

WPW: Wolff-Parkinson-White.

Characteristics of excluded studies [ordered by study ID] 


\begin{tabular}{ll}
\hline Study & Reason for exclusion \\
\hline Athar 2013 & $\begin{array}{l}\text { Not an RCT, as allocation to treatment was changed according to previous patient experience with } \\
\text { adenosine/verapamil. In addition, significant differences in baseline characteristics suggest that no } \\
\text { appropriate randomisation method was used. Study authors have not yet replied to our request for } \\
\text { further data/information. }\end{array}$ \\
\hline
\end{tabular}

\begin{tabular}{|c|c|}
\hline Ballo 2004 & Retrospective chart review and no relevant outcomes measured \\
\hline Belhassen 1984 & Review article, not a trial \\
\hline Conti 1995 & Editorial only \\
\hline DiMarco 1990 & Included participants with induced SVT \\
\hline Garratt 1989 & $\begin{array}{l}\text { Not a randomised trial. Participants with induced SVT were given adenosine, then were re-induced } \\
\text { and given verapamil. }\end{array}$ \\
\hline Gill 2014 & Not a randomised trial \\
\hline Hood 1992 & Included participants with induced SVT \\
\hline Kulakowski 1998 & Included participants with induced SVT \\
\hline Rankin 1991 & Review article, not a trial \\
\hline Riaz 2012 & $\begin{array}{l}\text { Significant differences in baseline characteristics suggest that no appropriate randomisation } \\
\text { method was used. Study authors have not yet replied to our request for further data/information. }\end{array}$ \\
\hline Sellers 1987 & Retrospective chart review \\
\hline Sethi 1994 & $\begin{array}{l}\text { Not a randomised trial. Participants with induced SVT were given adenosine, then were re-induced } \\
\text { and given verapamil. }\end{array}$ \\
\hline Shaker 2015 & Comparison of intravenous adenosine vs intravenous adenosine with oral verapamil \\
\hline Trappe 1997 & $\begin{array}{l}\text { Comparison of adenosine vs ajmaline (class } 1 \mathrm{~A} \text { antiarrhythmic). No calcium antagonist arm includ- } \\
\text { ed }\end{array}$ \\
\hline Turkoglu 1996 & Not a randomised trial \\
\hline Turkoglu 2009 & Only participants with induced SVT were included. \\
\hline
\end{tabular}

$\mathrm{RCT}$ : randomised controlled trial.

SVT: supraventricular tachycardia.

\section{DATA AND ANALYSES}


Comparison 1. Adenosine vs CCA

\begin{tabular}{|c|c|c|c|c|}
\hline Outcome or subgroup title & $\begin{array}{l}\text { No. of } \\
\text { studies }\end{array}$ & $\begin{array}{l}\text { No. of } \\
\text { partici- } \\
\text { pants }\end{array}$ & Statistical method & Effect size \\
\hline 1 Odds of reversion & 7 & 622 & Odds Ratio (M-H, Fixed, 95\% Cl) & $1.51[0.85,2.68]$ \\
\hline 2 Time to reversion (seconds) & 4 & & Mean Difference (IV, Fixed, 95\% CI) & Totals not selected \\
\hline 3 Relapse to SVT post reversion & 4 & 358 & Odds Ratio (M-H, Fixed, 95\% Cl) & $0.38[0.09,1.69]$ \\
\hline 4 Minor adverse events & 3 & & Odds Ratio (M-H, Fixed, 95\% Cl) & Subtotals only \\
\hline 4.1 Chest tightness & 3 & 222 & Odds Ratio (M-H, Fixed, 95\% Cl) & $0.09[0.02,0.50]$ \\
\hline 4.2 Shortness of breath & 2 & 171 & Odds Ratio (M-H, Fixed, 95\% Cl) & $0.23[0.04,1.37]$ \\
\hline 4.3 Flushing & 1 & 50 & Odds Ratio (M-H, Fixed, 95\% Cl) & $0.01[0.00,0.24]$ \\
\hline 5 Hypotension & 3 & 306 & Odds Ratio (M-H, Fixed, 95\% Cl) & $3.09[0.12,76.71]$ \\
\hline
\end{tabular}

Analysis 1.1. Comparison 1 Adenosine vs CCA, Outcome 1 Odds of reversion.

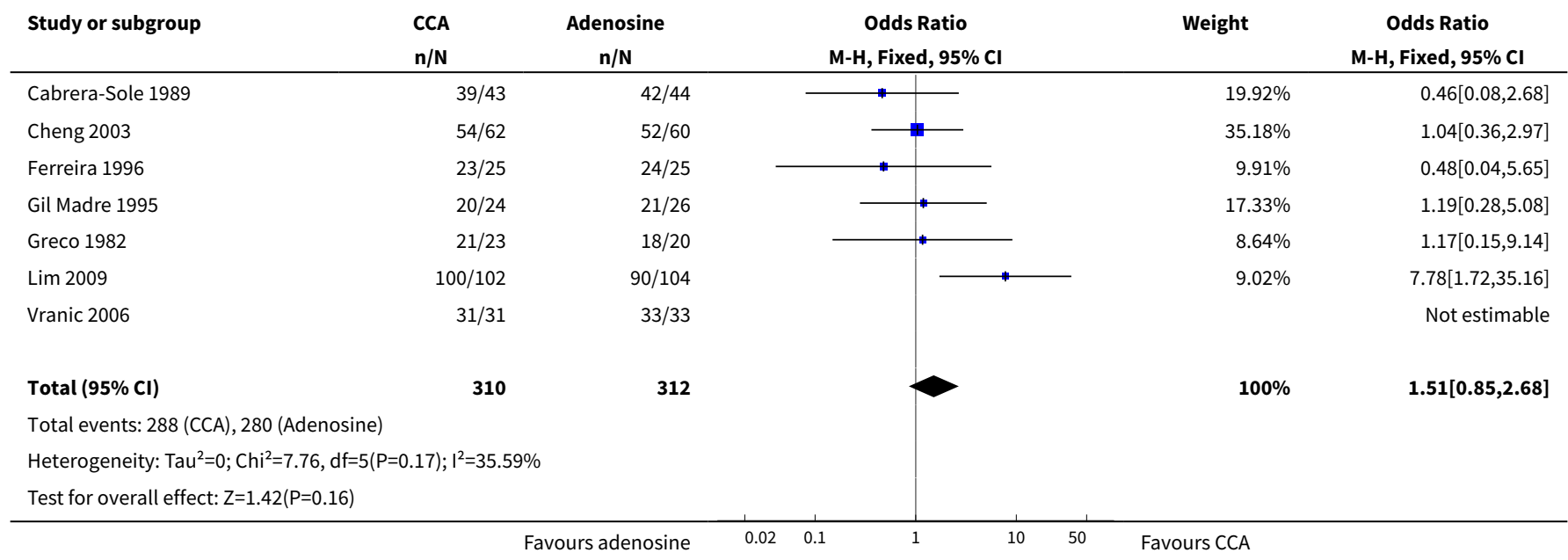

Analysis 1.2. Comparison 1 Adenosine vs CCA, Outcome 2 Time to reversion (seconds).

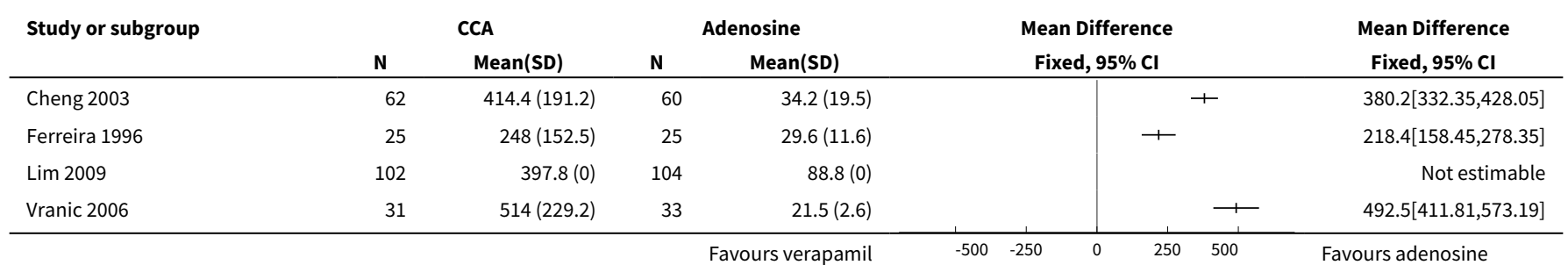


Analysis 1.3. Comparison 1 Adenosine vs CCA, Outcome 3 Relapse to SVT post reversion.

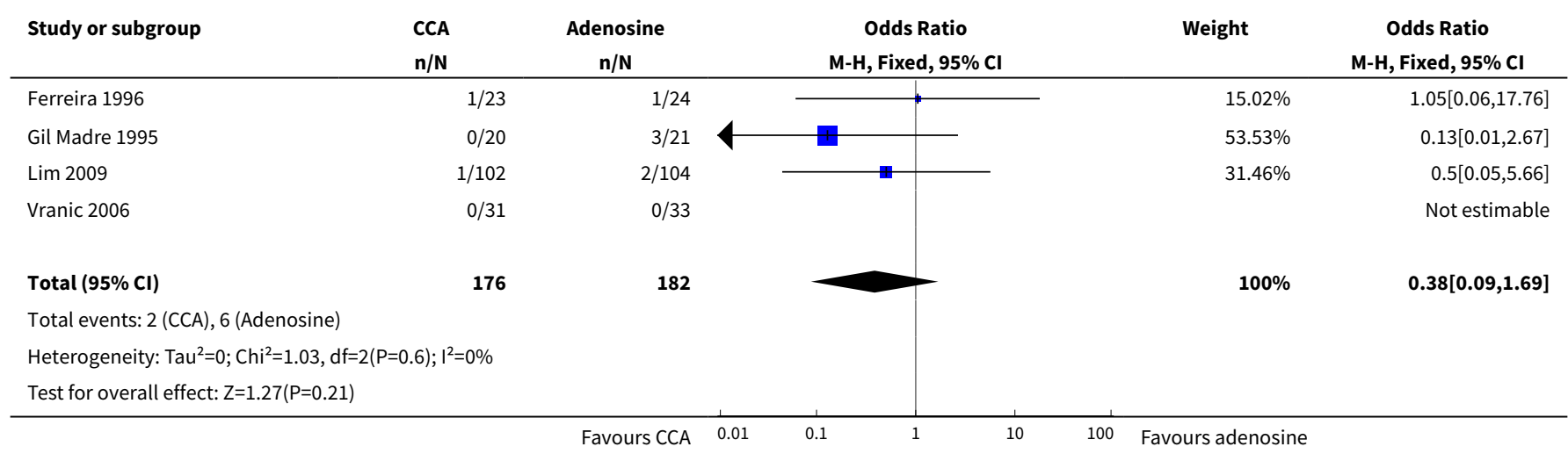

Analysis 1.4. Comparison 1 Adenosine vs CCA, Outcome 4 Minor adverse events.

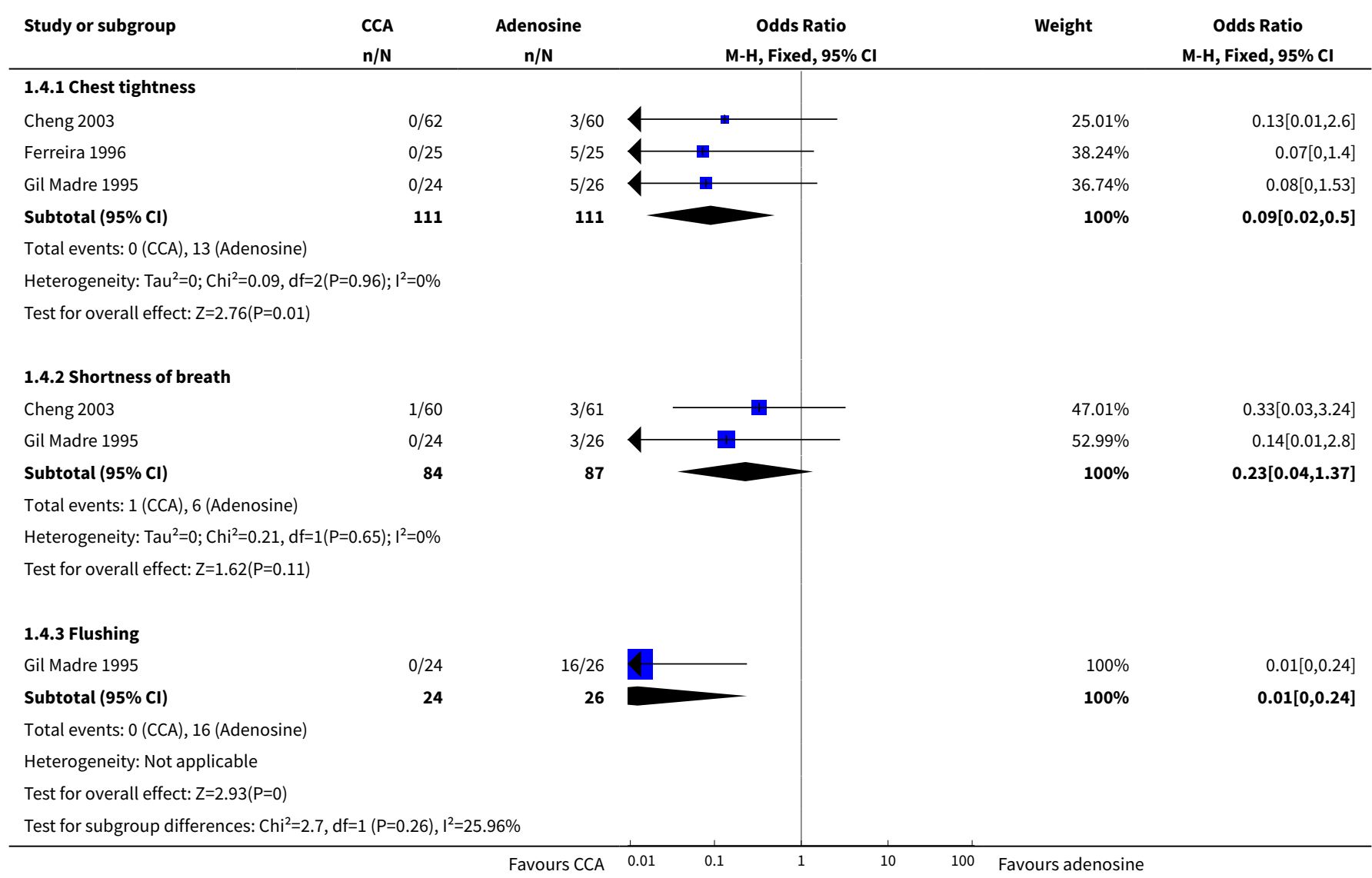


Analysis 1.5. Comparison 1 Adenosine vs CCA, Outcome 5 Hypotension.

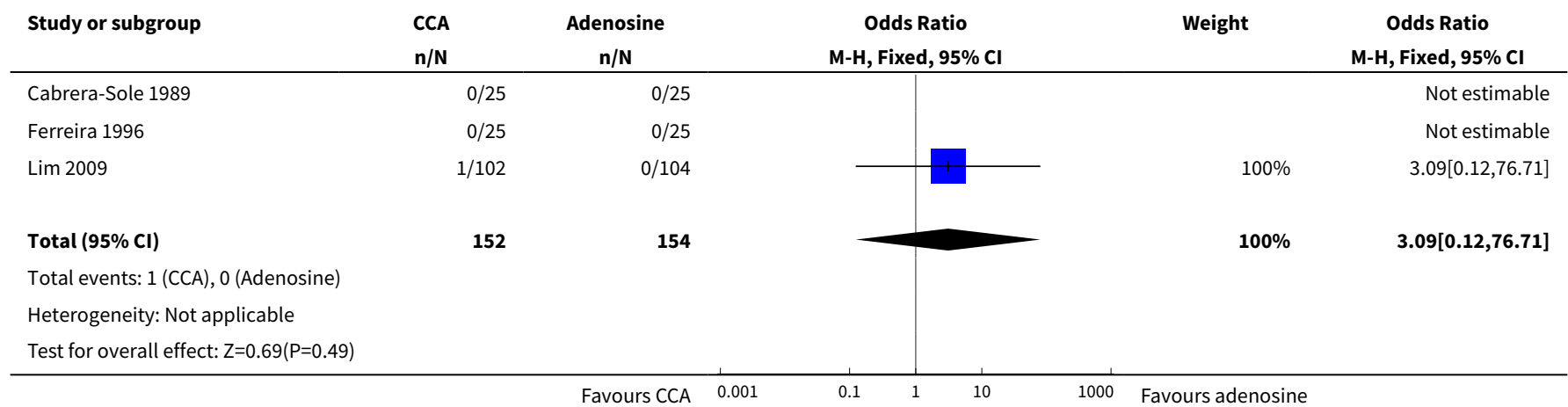

\section{APPENDICES}

\section{Appendix 1. Search strategy 2006}

\section{CENTRAL on the Cochrane Library}

$\# 1$ ADENOSINE

$\# 2$ adenosin*

\#3 (\#1 or \#2)

\#4 TACHYCARDIA SUPRAVENTRICULAR

\#5 (supraventricular next arrhythmia*)

\#6 tachycardia*

\#7 tachyarrhythmi*

\#8 (idioventricular next rhythm)

\#9 supraventric*

$\# 10$ svt

\#11 psvt

$\# 12$ (\#4 or \#5 or \#6 or \#7 or \#8 or \#9 or \#10 or \#11)

\#13 (\#3 and \#12)

\section{Ovid MEDLINE search strategy}

1 exp Adenosine/

2 adenosin $\$ . t w$.

31 or 2

4 exp Tachycardia, Supraventricular/

5 supraventricular tachycardia\$.tw.

6 supraventricular arrhythmia\$.tw.

7 supraventricular tachyarrhythmi\$.tw.

8 sinus tachycardia\$.tw.

9 svt.tw.

10 psvt.tw.

11 or/4-10

123 and 11

\section{Ovid Embase}

1 exp Adenosine/

2 adenosin $\$$.tw.

31 or 2

4 Heart Supraventricular Arrhythmia/

5 Supraventricular Tachycardia/

6 Paroxysmal Supraventricular Tachycardia/

7 supraventricular tachycardia\$.tw.

8 supraventricular arrhythmia\$.tw.

9 supraventricular tachyarrhythmi\$.tw.

10 sinus tachycardia\$.tw.

Adenosine versus intravenous calcium channel antagonists for supraventricular tachycardia (Review) 
11 svt.tw.

12 psvt.tw.

13 or $/ 4-12$

143 and 13

\section{Appendix 2. Search strategy 2017}

\section{CENTRAL}

\#1 MeSH descriptor Adenosine explode all trees

$\# 2$ adenosin*

\#3 (\#1 OR \#2)

\#4 MeSH descriptor Tachycardia, Supraventricular explode all trees

\#5 tachycardia*

\#6 supraventricular next arrhythmia*

\#7 tachyarrhythmi*

\#8 idioventricular next rhythm*

\#9 supraventric*

\#10 svt

\#11 psvt

\#12 (\#4 OR \#5 OR \#6 OR \#7 OR \#8 OR \#9 OR \#10 OR \#11)

\#13 (\#3 AND \#12)

\#14 (\#13), from 2010 to 2017

\section{MEDLINE}

1. exp Adenosine/

2. adenosin $\$ . t w$.

3. 1 or 2

4. exp Tachycardia, Supraventricular/

5. supraventricular tachycardia\$.tw.

6. supraventricular arrhythmia\$.tw.

7. supraventricular tachyarrhythmi\$.tw.

8. sinus tachycardia\$.tw.

9. svt.tw.

10. psvt.tw.

11. or/4-10

12. 3 and 11

13. randomized controlled trial.pt.

14. controlled clinical trial.pt.

15. randomized.ab.

16. placebo.ab.

17. drug therapy.fs.

18. randomly.ab.

19. trial.ab.

20. groups.ab.

21.13 or 14 or 15 or 16 or 17 or 18 or 19 or 20

22. exp animals/ not humans.sh.

23. 21 not 22

24. 12 and 23

25. $\left(2010^{\star}\right.$ or $2011^{\star}$ or $2012^{\star}$ or $2013^{\star}$ or $2014^{\star}$ or $2015^{\star}$ or $2016^{\star}$ or $\left.2017^{\star}\right)$.ed.

26. 24 and 25

\section{Embase}

1. adenosine/

2. adenosin $\$ . t w$.

3. 1 or 2

4. supraventricular tachycardia/

5. heart supraventricular arrhythmia/

6. paroxysmal supraventricular tachycardia/

7. supraventricular tachycardia\$.tw.

8. supraventricular arrhythmia\$.tw.

9. supraventricular tachyarrhythmi\$.tw.

10. sinus tachycardia\$.tw. 
11. svt.tw.

12. psvt.tw.

13. or/4-12

14. 3 and 13

15. random\$.tw.

16. factorial\$.tw.

17. crossover\$.tw.

18. cross over\$.tw.

19. cross-over\$.tw.

20. placebo $\$ . t w$.

21. (doubl\$ adj blind\$).tw.

22. (singl\$ adj blind\$).tw.

23. assign\$.tw.

24. allocat\$.tw.

25. volunteer\$.tw.

26. crossover procedure/

27. double blind procedure/

28. randomized controlled trial/

29. single blind procedure/

30.15 or 16 or 17 or 18 or 19 or 20 or 21 or 22 or 23 or 24 or 25 or 26 or 27 or 28 or 29

31. (animal/or nonhuman/) not human/

32. 30 not 31

33. 14 and 32

34. $\left(2010^{\star}\right.$ or $2011^{\star}$ or $2012^{\star}$ or $2013^{\star}$ or $2014^{\star}$ or $2015^{\star}$ or $2016^{\star}$ or $\left.2017^{\star}\right)$.dd, em.

35.34 and 35

Clinicaltrials.gov and the WHO International Clinical Trials Registry Platform (apps.who.int/trialsearch/)

adenosine And supraventricular tachycardia

WHAT'S NEW

\begin{tabular}{lll}
\hline Date & Event & Description \\
\hline 17 July 2017 & $\begin{array}{l}\text { New citation required and conclusions } \\
\text { have changed }\end{array}$ & $\begin{array}{l}\text { Exclusion of induced SVT } \\
\text { Included 2 new studies and added GRADEproGDT quality assess- } \\
\text { ment. }\end{array}$ \\
\hline 5 July 2017 & New search has been performed & New search \\
\hline
\end{tabular}

\section{H I S T O R Y}

Protocol first published: Issue 1, 2005

Review first published: Issue 4, 2006

\begin{tabular}{lll}
\hline Date & Event & Description \\
\hline 4 July 2016 & New search has been performed & Converted to new review format \\
\hline
\end{tabular}

\section{CONTRIBUTIONS OF AUTHORS}

S Alabed: selection of studies, data extraction and analysis, and review writing and editing.

A Sabouni: selection of studies and data extraction.

R Providencia: review editing and clinical expertise.

E Atallah: co-writing of review and data extraction. 
M Qintar: review editing, selection of studies, data extraction, and clinical expertise.

T JA Chicho: review editing, data extraction, and clinical expertise.

\section{DECLARATIONS OF INTEREST}

SA: none known.

AS: none known.

RP: has received a research grant from Medtronic for a clinical epidemiology study on sudden cardiac death, and proctored and lectured for Medtronic and Pfizer, respectively, on topics related to atrial fibrillation. However, these topics are not directly related to treatment of supraventricular arrhythmias (which do not include atrial fibrillation) in A\&E.

EA: none known.

MQ: none known.

T JA C: none known.

\section{SOURCES OF SUPPORT}

\section{Internal sources}

- None, Not specified.

\section{External sources}

- National Institute for Health Research (NIHR), UK.

S Alabed currently holds an NIHR Academic Clinical Fellowship (ACF)

- National Institutes of Health (NIH), USA.

M Qintar is supported by The National Heart, Lung, and Blood Institute of the NIH under Award Number T32HL110837

\section{DIFFERENCES BETWEEN PROTOCOL AND REVIEW}

\section{Differences between original review in 2006 and update in 2017}

The main changes in review methods compared with those used in the original review include the following.

1. Excluding studies of induced SVT: We excluded studies involving induced SVTs as they are not relevant to patients presenting acutely to the emergency department. Patients with inducible SVT may not necessarily be affected by SVT in their daily life. Induced SVTs can be terminated with pacing manoeuvres, whereas spontaneous SVTs treated in emergency rooms/A\&E may last for hours and may require IV treatment for control.

2. Excluding quasi-randomised trials: Although the review protocol mentioned inclusion of quasi-RCTs, we decided to exclude trials with major violations in randomisation methods or treatment allocation. We also excluded studies reported to be randomised but showing no data on baseline differences between treatment interventions, and those in which major differences occurred at a rate of $>1$ per 20 comparisons (which makes them unlikely to have occurred by chance) (Carlisle 2015; Carlisle 2017). When we had concerns about study methods, we excluded the study if study authors did not respond to our requests for clarification.

3. Using odds ratio instead of Peto odds ratio: The Cochrane Handbook for Systematic Reviews of Interventions discourages use of the Peto odds ratio and recommends use of the odds ratio instead (Higgins 2011).

4. Summary of findings tables: We prepared these in accordance with new requirements provided in the Cochrane Handbook for Systematic Reviews of Interventions.

5. Search for ongoing trials: The protocol and the original review did not plan or perform this.

6. Remove "in adults" from title: The protocol did not attempt to include adults only, and the original review included only one study in children (Greco 1982).

\section{N DEX TERMS}

\section{Medical Subject Headings (MeSH)}

Adenosine [adverse effects] [^therapeutic use]; Anti-Arrhythmia Agents [adverse effects] [therapeutic use]; Calcium Channel Blockers [adverse effects] [ ${ }^{\star}$ therapeutic use]; Emergency Service, Hospital [statistics \& numerical data]; Hypotension [chemically induced]; Randomized Controlled Trials as Topic; Tachycardia, Supraventricular [*drug therapy]; Verapamil [adverse effects] [therapeutic use] 


\section{MeSH check words}

Adult; Humans 